\title{
ESTUDIO DOGMÁTICO Y JURISPRUDENCIAL SOBRE LA AGRAVANTE DE DISCRIMINACIÓN POR RAZONES DE GÉNERO $^{1}$
}

\author{
Bárbara San Millán Fernández²
}

Resumen: la agravante de discriminación por razones de género se incorporó, al art. 22. $4^{\mathrm{a}} \mathrm{CP}$, por la LO 1/2015, de 30 de marzo. El examen de las sentencias dictadas, desde entonces, por las distintas Audiencias Provinciales y Tribunales Superiores de Justicia revela una contradictoria aplicación de la circunstancia, que lesiona, gravemente, la seguridad jurídica. Asimismo, desde que dictara su primera sentencia sobre el particular-STS 420/2018, de 25 de septiembre- y a pesar del breve periodo de tiempo transcurrido, el Tribunal Supremo ha cambiado de criterio, de forma sustancial, en relación con el fundamento y requisitos aplicativos de esta agravante. En este contexto, en la presente investigación, se propone, desde una perspectiva dogmática, una interpretación objetiva de la agravante de discriminación por razones género, a la luz de la cual se analizan su compatibilidad con la agravante de parentesco y su régimen de comunicabilidad a los partícipes del delito.

Recibido: marzo 2019. Aceptado: mayo 2019

1 Este trabajo se ha realizado en el seno del Proyecto de Investigación I+D+I DER2016-77228-P.

2 Profesora Ayudante LOU. ORCID ID 0000-0002-9389-9515

Departamento de Derecho Público. Universidad de Cantabria. Avda. de los Castros s/n. 39005 Santander. E-mail: sanmillanb@unican.es 
Palabras clave: circunstancias agravantes, discriminación, violencia de género, violencia doméstica, victimización.

\title{
DOGMATIC AND JURISPRUDENTIAL STUDY ABOUT THE AGGRAVATING OF DISCRIMINATION BASED ON GENDER
}

\begin{abstract}
: the aggravating of discrimination based on gender was incorporated, to art. 22. 4th CP, by LO 1/2015, of March 30. The examination of the judgments handed down, since then, by the various Provincial Courts and Superior Courts of Justice reveals a contradictory application of the circumstance, which seriously injures juridical security. Also, since it issued its first ruling on the subject -STS 420/2018, of September 25- and despite the brief period of time that has elapsed, the Supreme Court has changed its criteria, substantially, in relation to the rationale and application requirements of this aggravating. In this context, in the present investigation, it is proposed, from a dogmatic perspective, an objective interpretation of the aggravating circumstance of gender discrimination, in light of which its compatibility with the aggravation of kinship and its communicability regime is analyzed.
\end{abstract}

Keywords: aggravating circumstance, discrimination, gender violence, domestic violence, victimization.

\section{Estado de la cuestión ${ }^{3}$}

La comisión de un delito por motivos discriminatorios constituye, como es sabido, una agravante genérica de la responsabilidad criminal $^{4}$, susceptible de aplicación, por lo tanto, a

3 Este trabajo se ha realizado en el seno del Proyecto de Investigación I+D+I DER2016-77228-P.

4 La agravante se introdujo, en el Código penal anterior, por la LO 4/1995, de 11 de mayo, de modificación del Código penal, mediante la que se tipifica la apología de los delitos de genocidio, con el siguiente tenor: "[c]ometer cualquiera de los delitos contra las personas o el patrimonio por motivos racistas, antisemitas u otros referentes al origen étnico o nacional, o a la ideología, religión o creencias de la víctima” (art. 10. 17ª TRCP de 1973). La Exposición de Motivos justificó la aprobación de dicha LO, a pocos meses de la entrada en vigor del CP de 1995, porque "[1]a proliferación en distintos países de Europa de episodios de violencia racista y antisemita que 
todos los delitos de la parte especial -excepción hecha de aquellos en los que el legislador ya haya tenido en cuenta esta circunstancia a la hora de tipificar la conducta-. El art. 22. $4^{\text {a }} \mathrm{CP}$ enumera las causas en las que puede basarse dicha discriminación para dar lugar a la apreciación de la agravante, aun cuando, como advierte CÓRDOBA RODA ${ }^{5}$, el art. 14 CE no establece un numerus clausus, sino que prohíbe toda clase de discriminación, ya sea por razón de nacimiento, raza, sexo, religión u opinión -motivos expresamente enumerados en el precepto-, ya por "cualquier otra condición personal o social". En su redacción originaria, el art. 22. $4^{\mathrm{a}} \mathrm{CP}$ incluía los motivos racistas, antisemitas, ideológicos, religiosos o basados en las creencias de la víctima, la etnia, raza o nación a la que perteneciera, su sexo u orientación sexual, o la enfermedad o minusvalía que la misma padeciera. La LO 5/2010, de 22 de junio, añadió, a este elenco de supuestos, la "identidad sexual" y sustituyó el término "minusvalía" por el de "discapacidad". Finalmente, la LO 1/2015, de 30 de marzo, ha incorporado una nueva causa de discriminación que dará lugar a la apreciación de la agravante, "las razones de género", cuya interpretación por parte de la jurisprudencia, habiéndose cumplido tres años desde la entrada en vigor de la reforma, será objeto de análisis, desde una perspectiva dogmática, en el presente estudio.

se perpetran bajo las banderas y símbolos de ideología nazi, obligan a los Estados democráticos a emprender una acción decisiva para luchar contra ella", afirmando, seguidamente, que "[p]or desgracia, España no ha permanecido ajena al despertar de este fenómeno, circunstancia que se agrava por el hecho de que la legislación española no contempla suficientemente todas las manifestaciones que este fenómeno genera".

5 CÓRDOBA RODA, J.: “Art. 22”, en CÓRDOBA RODA, J. y GARCÍA ARÁN, M., Comentarios al Código penal. Parte general, Barcelona, 2011, p. 290. 


\section{La circunstancia agravante de discriminación por razones de género en la jurisprudencia}

A efectos sistemáticos, distinguiremos, en relación con la aplicación jurisprudencial del precepto, dos periodos: un primer periodo, que abarca desde la entrada en vigor de la LO 1/2015 hasta la fecha de la primera sentencia del TS en la que se pronuncia sobre el particular-STS 420/2018, el 25 de septiembre$\mathrm{y}$ un segundo periodo, que va desde la fecha indicada hasta el 26 de febrero de 2019, en el cual, y pese a su brevedad, hemos podido asistir a cambios sustanciales de criterio de la Sala $2^{\mathrm{a}}$ del TS en relación con la agravante de discriminación por razones de género, en sus SSTS 565/2018, de 19 de noviembre, y 99/2019, de 26 febrero.

\subsection{La circunstancia agravante de discriminación por razones de género en la "jurisprudencia menor"}

La incorporación de la circunstancia agravante de discriminación por razones de género a nuestro Código penal hizo surgir dos importantes interrogantes ${ }^{6}$. El primero de ellos, referido a su fundamento $y$, por ende, a su compatibilidad con la circunstancia de parentesco con efectos agravantes (art. $23 \mathrm{CP}$ ) y a su distinción con la circunstancia de discriminación por razón de sexo, ya prevista en el mismo art. 22. $4^{\mathrm{a}} \mathrm{CP}$. El segundo, relacionado con los requisitos que deben concurrir para la apreciación de dicha agravante.

Numerosas sentencias se han dictado, desde entonces, por las distintas Audiencias Provinciales y Tribunales Superiores de Justicia sobre el tema, coincidiendo, en la práctica totalidad de los casos enjuiciados, el supuesto de hecho: un delito de homicidio o asesinato, consumado o intentado, cometido por un varón contra su esposa, exesposa, pareja o expareja sentimental. Sin embargo, el examen de estas resoluciones pone de relieve

6 BORJA JIMÉNEZ, E.: "La circunstancia agravante de discriminación del art. 22. 4", en GONZÁLEZ CUSSAC, J. L. (dir.), Comentarios a la Reforma del Código Penal de 2015, Valencia, 2015, pp. 121 y 122. 
que, en casos muy similares -cuando no, prácticamente idénticos-, la jurisprudencia ha sido contradictoria. Por ello, en este epígrafe, nos proponemos, de un lado, exponer el tratamiento que los Tribunales penales han ofrecido a los interrogantes antes aludidos, para, posteriormente, someterlo a análisis crítico; $\mathrm{y}$, de otro, evidenciar las notorias incongruencias que se han detectado en la valoración de hechos análogos y que han dado lugar a soluciones contrapuestas, lesionando, gravemente, la seguridad jurídica.

\subsubsection{Fundamento, compatibilidad y requisitos para la} aplicación de la circunstancia

En el periodo que estamos analizando, la "jurisprudencia menor" ha considerado, de forma unánime, que la circunstancia agravante de discriminación por razones de género es "una circunstancia de carácter subjetivo", cuyo fundamento se halla en "la mayor culpabilidad del autor por la mayor reprochabilidad del móvil que le impulsa a cometer el delito"7. Dicho móvil no es otro que el propósito de discriminar o de hacer patente la situación de desigualdad o la relación de poder de un hombre sobre una mujer, que sea o haya sido su cónyuge o que esté o haya estado ligada a él por una análoga relación de afectividad, aún sin convivencia ${ }^{8}$. En otras palabras, el delito cometido debe ser "expresión de su idea de dominación" sobre la mujer con la que mantenga o haya mantenido una relación conyugal o análo$\mathrm{ga}^{9}$. Este nuevo motivo de discriminación, como señala la SAP

7 Entre otras, SAP de Cantabria 204/2018, de 7 de junio; SAP de Madrid 514/2018, de 16 de julio; SAP de Badajoz 5/2018, de 5 de febrero, o SAP de Vizcaya, 34/2018, de 26 de abril.

8 Así, la SAP de Madrid 514/2018, de 16 de julio.

9 SAP de Badajoz 5/2018, de 5 de febrero. Continúa la citada sentencia afirmando que "tal como se desprende de lo señalado en la STS 314/2015, de 4 de mayo (RJ 2015, 3537), en la que se aplicó la agravante por motivos racistas, si bien sus razonamientos pueden servir de orientación para interpretar la nueva agravante de actuar por motivos de género (...) la mayor sanción del hecho se justifica porque el delito cometido por motivos discriminatorios supone la materialización mediante hechos delictivos de ideas 
de Cantabria 204/2018, de 7 de junio, no puede identificarse con "la simple diferencia entre los sexos del sujeto activo y pasivo del delito (igual o diferente al del sujeto activo), pues estas dos motivaciones pueden considerarse ya incluidas en la locución «(su sexo» que existía en la regulación anterior"10.

De las anteriores afirmaciones podemos extraer ya el primer requisito exigido por los Tribunales penales para la apreciación de la agravante de discriminación por razones de género: el sujeto activo del delito ha de ser un varón, mientras que el sujeto pasivo ha de ser una mujer, que, además, debe encontrarse o haberse encontrado unida a aquel por matrimonio o por una relación análoga, aun sin convivencia. La exigencia de esta última condición implica que la aplicación de la agravante de género se ha planteado, únicamente, en supuestos en los que, además, podía concurrir la agravante de parentesco del art. $23 \mathrm{CP}$, ya que, entre los sujetos que esta última enumera, se encuentran el cónyuge o la persona que esté o haya estado ligada, de forma estable, por una análoga relación de afectividad con el ofensor ${ }^{11}$. Por tal motivo, la "jurisprudencia menor" se ha pronunciado acerca de la compatibilidad entre ambas circunstancias, afirmando -con alguna excepción ${ }^{12}$ - que son plenamente compatibles,

contrarias a un valor constitucional esencial, el principio de igualdad o, lo que es lo mismo, la prohibición del trato discriminatorio, por lo que se lesiona el bien jurídico protegido por el delito concreto y, además, el principio constitucional de igualdad". Del mismo modo, SAP de Madrid 514/2018, de 16 de julio.

10 En idéntico sentido, SAP de Badajoz 5/2018, de 5 de febrero, y SAP de Madrid 514/2018, de 16 de julio.

11 El ámbito de aplicación de estas dos circunstancias no era, no obstante, exactamente coincidente, pues la agravante de parentesco exige el carácter estable de la relación, lo que ha sido interpretado por la jurisprudencia como la necesidad de convivencia entre los sujetos del delito, mientras que la agravante de discriminación por razones de género se ha considerado aplicable, también, en el caso de relaciones de afectividad análogas a la matrimonial, aún sin convivencia. Véase, al respecto, la STS 420/2018, de 25 de septiembre.

12 En sentido contrario se pronuncia la SAP de Asturias 2/2018, de 26 de enero, que considera incompatibles la agravante de parentesco y la de discrimi- 
pues, si bien la agravante de parentesco se funda "en los vínculos familiares y de afectividad, presentes o pasados en el caso de cónyuges o parejas de hecho", la agravante de discriminación por razones de género lo hace en "el hecho de haberse cometido el delito con una determinada motivación, relacionada con la condición de la víctima como mujer por razones de su género"13.

Por lo tanto, según la "jurisprudencia menor", los requisitos para la aplicación de la agravante de discriminación por razones de género son los siguientes:

1. Que el sujeto activo del delito sea un varón.

2. Que el sujeto pasivo sea una mujer, que, además, sea o hay sido esposa o se encuentre o se haya encontrado unida a aquel por una relación análoga de afectividad.

3. Que el delito se haya cometido con el propósito de ejercer su dominio, superioridad y control sobre la víctima por el hecho de ser mujer, lo que significa que “deberán imputarse por las acusaciones, y probarse por ellas, una serie de hechos circunstanciales de los que se infiera, sin duda alguna, que el autor actuó por ese motivo"14.

Sentado lo anterior, pasaremos a analizar cómo los Tribunales penales han aplicado, en la práctica, la circunstancia agravante objeto de estudio.

2.1.2. La agravante de discriminación por razones de género concurre:

nación por razones de género, afirmando que "el Jurado, a pesar de declarar probado que entre Carla y Jerónimo hubo una relación sentimental seria, estable y con vocación de permanencia, no aprecia la concurrencia de la agravante de parentesco propuesta por las dos acusaciones, probablemente por considerar que, en este caso, esa relación sentimental (...) es el presupuesto necesario de la agravante de discriminación por razón de género, sí apreciada y que por tanto absorbe la de parentesco".

13 SAP Tenerife 64/2017, de 23 de febrero; SAP de Vizcaya, 34/2018, de 26 de abril; SAP de Cantabria 204/2018, de 7 de junio.

14 SAP de Badajoz 5/2018, de 5 de febrero. 


\section{A) Si los hechos se cometen "en el seno de una rela- ción tendente por el hombre a expresar el dominio, control y trato a la mujer como ser inferior": SAP de Vizcaya 34/2018, de 26 de abril}

Según consta en los "Hechos Probados" descritos en la SAP de Vizcaya, 34/2018, de 26 de abril, el acusado, "no habiendo aceptado la ruptura de su matrimonio con Inocencia, movido por el ánimo de acabar con la vida de esta", acudió a su domicilio y, tras abrirle ella la puerta, de forma sorpresiva, le tapó la boca y la nariz presionándola fuertemente con las manos, llevándola al baño y golpeándola en la cabeza con el escalón de la bañera hasta dejarla en estado de inconsciencia o semiinconsciencia. A continuación, la trasladó en el maletero de su coche hasta una carretera en la que, "tratando de simular un accidente", la tendió en el asfalto y la arrolló con el coche, causándole la muerte. El acusado fue condenado por un delito de asesinato con las circunstancias agravantes de parentesco y discriminación por razón de género, por considerarse probado que los hechos cometidos "están relacionados con la condición de mujer que tenía Inocencia, esto es, en el seno de una relación tendente por el hombre a expresar el dominio, control y trato a la mujer como ser inferior ${ }^{15}$ ", lo que se manifiesta en el control de los ingresos ejercido por el acusado durante el matrimonio y, tras la separación, de las redes sociales de la víctima y los mensajes reiterados e insistentes por WhatsApp, las preguntas a los allegados de la víctima acerca de la posibilidad de que ella tuviera una nueva pareja y, en fin, el pago de 600 euros por parte del acusado a un vidente "para que le hiciese un conjuro a fin de recuperar a Inocencia". De todo ello, considera el Tribunal, "se desprende una específica motivación del acusado, que no aceptó la ruptura de la relación y que reaccionó causando la muerte de su exmujer, en particular cuando ve que ella persiste en continuar su vida con independencia (...) estando ya fuera de su control y dominio".

15 Con cursiva en el original. 


\section{B) Si los hechos se cometen "desconociendo las con- diciones de igualdad como habitual modo de rela- ción en la pareja": SAP de Cantabria 204/2018, de 7 de junio}

Numerosas similitudes con el caso expuesto presentan los hechos enjuiciados por la SAP de Cantabria 204/2018, de 7 de junio. El acusado, que había mantenido una relación sentimental sin convivencia con la víctima, tras la ruptura de dicha relación por parte de la mujer -ruptura que, según consta, el acusado no aceptaba- se encontró con ella y le recriminó "estar paseando por la calle a esas horas". Posteriormente, acudió a su domicilio para hablar con ella en el portal y tratar de convencerla para reanudar la relación. Comoquiera que ella no aceptó, "le advirtió que era la última noche para los dos y que iban a morir juntos", propinándole, seguidamente, una serie de cuchilladas. Alertado por los gritos de la mujer, acudió en su auxilio su compañero de piso, huyendo, entonces, el acusado sin lograr su propósito de matarla. La AP de Cantabria le condenó por un delito de homicidio en grado de tentativa, concurriendo la circunstancia agravante de discriminación por razones de género, al considerar que la intención de cometer el delito contra la mujer, por el hecho de ser mujer y como acto de dominio y superioridad, queda acreditada, en el presente caso, por "las declaraciones de los testigos que revelan una situación de discriminación y dominio efectuado por el procesado que se manifestó exteriormente por el enfado de este al encontrarse a Adoración por la noche paseando con una amiga sabiendo que estaba embarazada de él, por el control de ir a su domicilio a buscarla a altas horas de la madrugada y esperarla hasta que llegara, de despertar a la anterior pareja de Adoración para preguntar por ella y de si estaba con otro, de no aceptar la ruptura de la pareja que ella unilateralmente decidió y de las manifestaciones que realizó en el momento de la comisión del hecho delictivo. Todos estos actos revelan que el procesado, desconociendo las condiciones de igualdad como habitual modo de relación en la pareja $^{16}$, se encontraba ejerciendo un control

16 La cursiva es nuestra. 
sobre la vida y sentimientos de Adoración, queriendo anular su voluntad de decisión y de respeto sobre sí misma, hasta acabar con su vida, como acto final de dominación".

\section{C) $\mathrm{Si}$ los hechos se cometen por "no consentir que como mujer llevara una vida independiente y ple- na": SAP de Tenerife 64/2017, de 23 de febrero}

También la AP de Tenerife dicta su sentencia 64/2017, de 23 de febrero, en relación con un supuesto muy semejante a los expuestos. El acusado, que había mantenido una relación de pareja por un tiempo aproximado de cuatro años con la víctima, entró en la tienda en la que esta trabajaba y, con la intención de acabar con su vida, la roció con gasolina y la prendió fuego, causándole quemaduras en el $95 \%$ de su cuerpo, las cuales, junto con la inhalación de humo, provocaron su muerte. El acusado resultó condenado por un delito de asesinato, con las circunstancias agravantes de parentesco y de discriminación por razones de género. En relación con la aplicación de esta última circunstancia, se declara probado que "Fulgencio nunca aceptó la decisión de Lina de poner fin a su relación y causó su muerte, al no consentir que como mujer llevara una vida independiente y plena $^{17}$, así como por no poder seguir ejerciendo su dominio, superioridad y control sobre ella". De este hecho se desprende, según afirma la AP de Tenerife, una específica motivación del acusado, que no aceptó la ruptura de la relación y que reaccionó causando la muerte de su expareja, "en particular cuando ella persiste en continuar su vida con independencia, tiene un nuevo empleo que le resulta satisfactorio o se abre a diferentes relaciones personales".

2.1.3. La agravante de discriminación por razones de género no concurre, por no entenderse probado el propósito discriminatorio:

17 La cursiva es nuestra. 


\section{A) Aunque el hombre cometa el delito por "no acep- tar la ruptura" con la mujer, tras acosarla y ame- nazarla de muerte: SAP de Lleida 379/2017, de 18 de octubre}

Conforme a los "Hechos probados" relatados en la SAP de Lleida 379/2017, de 18 de octubre, el acusado había mantenido con la víctima una relación sentimental, que había finalizado por decisión de la mujer. Según consta, dicha ruptura "no fue del todo aceptada por el acusado", que continuó comunicándose con ella mediante llamadas - hasta 63 veces en un día-, mensajes de Whatsapp y Facebook, terminando ella por bloquearle. Logró, finalmente, contactar con la mujer a través de terceras personas, accediendo esta a encontrarse con él para darle una explicación sobre las causas de la ruptura. Aun así, continuó el acusado enviando mensajes en los que decía: "lo voy a matar", "lo voy a kitar la vida", refiriéndose a la actual pareja de la mujer, y "me tengo ke matar aki en la carretera de andorra pake lo veas?", "tu no volveras conmigo... pero antes de k muera yo la lio petarda", así como "si me kedo te voy a joder", insistiéndole en quedar para verse una última vez antes de trasladarse él a vivir a otra ciudad, lo que ella aceptó. Cuando la mujer llegó al lugar convenido, él la invitó a subir al coche. En un determinado momento, el acusado comenzó a acelerar el vehículo, mientras le decía que "la única solución es que lo arreglemos juntos", "si no eres para mí, no eres para nadie" y "nos vamos a matar juntos", para terminar por dirigir el turismo contra otro que circulaba correctamente por el carril contrario, cuyo conductor logró evitar la colisión frontal, pero no impedir el choque entre ambos vehículos. Tanto la mujer como el conductor del otro vehículo sufrieron lesiones de diversa entidad.

El acusado resultó condenado por dos delitos de homicidio en grado de tentativa, rechazando la AP de Lleida, en relación con el delito cometido contra su expareja, la concurrencia de la circunstancia agravante de discriminación por razones de género solicitada por las acusaciones. En este sentido, argumenta, acerca de la insistencia del acusado en contactar con la 
mujer, que, "aunque esta porfía permitiría contextualizar los hechos que ocurrieron con posterioridad, o incluso podrían llegar a ser indicadores del perfil personal del acusado, en cambio, en sí mismas, son insuficientes para deducir de ellas que el delito se hubiera cometido con el propósito de discriminar o de hacer patente la situación de desigualdad o la relación de poder sobre la víctima ${ }^{18}$, y menos aun cuando este desequilibrio relacional tampoco se había manifestado durante su relación sentimental”.

Esta sentencia de la AP de Lleida presenta una manifiesta contradicción con las resoluciones que hemos examinado anteriormente. El supuesto de hecho es prácticamente idéntico a los relatados por las citadas sentencias de las Audiencias Provinciales de Vizcaya, Cantabria y Tenerife, que, como hemos expuesto, apreciaron la concurrencia de la agravante de discriminación por razones de género: un varón que no acepta la ruptura de la relación sentimental con una mujer y que, contra la voluntad de esta última, trata, de forma insistente, de comunicarse con ella y retomar la relación. Puesto que no logra dicho objetivo, intenta matarla, manifestando, de forma expresa, tal como resulta probado, que "la única solución es que lo arreglemos juntos" y "si no eres para mí, no eres para nadie". De estos hechos se desprende, de forma clara, que el acusado cometió el delito por no aceptar la decisión de la mujer de poner fin a la relación que mantenían y de iniciar una nueva relación con otra persona, como manifestación de "dominio, superioridad y control sobre ella" ${ }^{19}$. Asimismo, ni en la SAP de Vizcaya -salvo el control de los ingresos durante el matrimonio- ni en la SAP de Cantabria, ni en otras resoluciones similares ${ }^{20}$, consta si ese "desequilibrio relacional" se había manifestado o no durante el tiempo en que el sujeto activo y pasivo habían mantenido una relación conyugal o sentimental -lo que, por otro lado, en ningún caso se desprende de la letra de la Ley-, bastando, para considerar acre-

18 La cursiva es nuestra.

19 SAP de Tenerife $64 / 2017$, de 23 de febrero.

20 Véase, SAP de Tenerife 64/2017, de 23 de febrero. 
ditado el propósito discriminatorio que fundamenta la aplicación de la agravante, con la prueba de hechos posteriores a la ruptura de los que se infiera tal motivación.

B) Aunque el hombre cometa el delito "por razones de impedir la separación, con los efectos personales y patrimoniales que pensó iban a producirse": STSJ de Aragón 17/2018, de 4 de mayo

Problema similar se plantea en la STSJ de Aragón 17/2018, de 4 de mayo, que estima, en parte, el recurso de apelación interpuesto contra la Sentencia, dictada por el Tribunal del Jurado constituido en la Audiencia Provincial de Zaragoza, de 30 de noviembre de 2017. En el caso en cuestión, el acusado, marido de la víctima, "no aceptaba los criterios económicos formulados por su esposa, como consecuencia de la separación o divorcio: le angustiaba en particular que su mujer le plantease que iba a reclamar los derechos que legalmente le pudieran corresponder, también le angustiaba que su esposa le pidiera que quería asesorarse por terceros, a fin de reclamar lo que pudiera corresponderle económicamente, a raíz de la separación". Por ello, mientras ella se encontraba en la cama "dormida o semidormida o simplemente desprevenida", le asestó varias puñaladas hasta causarle la muerte. En la sentencia de instancia, que condenó al acusado por un delito de asesinato, concurriendo más de una de las circunstancias previstas en el art. 139.1 CP -alevosía $\mathrm{y}$ ensañamiento- $\mathrm{y}$ las agravantes de parentesco y de discriminación por razones de género, se declara probado que "las acciones llevadas a cabo por el encausado están dentro de una relación de dominación. Tales acciones tienen su origen inmediato en la decisión de la víctima de solicitar el divorcio. Durante el matrimonio el encausado había impuesto sus condiciones en el estilo de vida de la pareja, haciendo prevalecer sus decisiones en todos los temas importantes, alejándola y aislándola paulatinamente de su familia y su entorno". Sin embargo, el TSJ de Aragón considera que resulta procedente la estimación del motivo de recurso, "pues en el comportamiento del autor no consta que actuara 
por motivos de discriminación, odio o desprecio a las mujeres, sino por razones de impedir la separación, con los efectos personales y patrimoniales que pensó iban a producirse" ${ }^{21}$. En este caso, por lo tanto, había resultado acreditado que ese "desequilibrio relacional", del que hablaba la SAP de Lleida antes citada, se había manifestado durante el tiempo en el que los sujetos habían mantenido una relación conyugal y, sin embargo, en esta ocasión, el TSJ de Aragón no lo considera suficiente para acreditar que el delito fuera cometido por razones de género. Pero tampoco estima que acabar con la vida de su mujer "para impedir la separación, con los efectos personales y patrimoniales que pensó iban a producirse" constituyera una más que evidente expresión de dominio sobre ella ${ }^{22}$.

\section{C) Aunque el hombre cometa el delito, movido por los celos, porque la víctima se niegue a la entrega de su teléfono móvil: SAP de A Coruña 198/2017, de 2 de mayo}

Semejantes cuestiones se suscitan en la SAP de A Coruña 198/2017, de 2 de mayo, en relación con un supuesto en el que el acusado, que mantenía una relación sentimental con la víctima desde hacía ocho años, ante la recepción por parte de la mujer de unos mensajes de Whatsapp, "empezó a ponerse nervioso y celoso, preguntándole quién se los mandaba al mismo tiempo que le pedía que le entregara el teléfono móvil", a lo que ella se negó, clavándole él, entonces, un cuchillo de cocina en el abdomen, que no le produjo la muerte, pero sí lesiones que requirieron de intervención quirúrgica para su curación. Sostiene el Tribunal que "las acusaciones en sus respectivos relatos fácticos de imputación no recogieron ningún hecho o circunstancia de la que se desprenda que el procesado actuó, además de con dolo de matar/lesionar, por un motivo discriminatorio para su com-

21 La cursiva es nuestra.

22 La STS 67/2019, de 25 de enero, ha estimado el recurso de casación interpuesto contra la STSJ de Aragón 17/2018, de 4 de mayo, y considera aplicable la circunstancia agravante de discriminación por razones de género.

Estudoos Penales Y CRIMINOĹóGicos, vol. XXXIX (2019). ISSN 1 137-7550: 589-642 -316- hitp://dx.doi.org/10.15304/epc.39.5925 
pañera sentimental, sino más bien al contrario habida cuenta que imputaron que se produjo una discusión entre la pareja por motivos de celos y el hombre cogió un cuchillo y se lo clavó" y que "sólo ha quedado probado que ante la negativa de María Esther a darle el teléfono él la pinchó en el abdomen con el cuchillo que había cogido de la cocina, sin poder colegir de esa acción que actuó, además, con un ánimo específico de desprecio y discriminación hacia la mujer que era su pareja sentimental. Consecuentemente, no existen elementos para apreciar la agravante de género interesada por las acusaciones" ${ }^{23}$. Esta argumentación no puede sino causar perplejidad. El acusado cometió el delito porque no aceptó que ella le negara la entrega del teléfono, no pudiendo, de este modo, controlar las comunicaciones de su pareja. Ello constituye una manifestación inequívoca de dominio, de superioridad sobre la misma, derivada, en expresión de la SAP de Valencia 145/2017, de 3 de marzo, del "entendimiento por parte del sujeto activo de la necesidad de sumisión y obediencia que, por razón de ser la víctima mujer, le debe”.

\subsection{La circunstancia agravante de discriminación por} razones de género en la jurisprudencia del tribunal supremo

2.2.1. STS (Sala de lo penal, secc. $1^{a}$ ) 420/2018, de 25 de septiembre

En este contexto, caracterizado por una jurisprudencia absolutamente contradictoria, el TS dicta su sentencia 420/2018, de 25 de septiembre, primera resolución en la que conoce de la aplicación de la circunstancia agravante de discriminación por razones de género. Los hechos declarados probados por el Tribunal de instancia presentan, como se comprobará, importantes analogías con algunos de los casos que hemos analizado hasta ahora. El acusado y la víctima, mujer con la que mantenía una relación de afectividad desde hacía más de un año, acudieron a casa de una amiga a "charlar, oir música y tomar unas cervezas".

23 La cursiva es nuestra. 
En un momento dado, el acusado le quitó el móvil a su pareja, "al estar esta atendiendo al mismo, movido por los celos de que pudiese estar comunicando con otro hombre, y guardándoselo en el bolsillo pese a que Elisa le pidió que se lo devolviera". Poco después, el acusado se dirigió a la cocina y se hizo con un cuchillo que guardó en el bolsillo de sus pantalones. Posteriormente, la mujer acudió al baño, cerrando la puerta sin echar el pestillo y, "cuando se encontraba orinando, sentada en el inodoro y con los pantalones y ropa interior bajadas, entró el acusado, que, aprovechando la situación en que se encontraba Elisa, con limitada capacidad de movimientos, sacó el cuchillo que llevaba escondido y se abalanzó sobre ella dándole cuchilladas, al tiempo que profería expresiones como «si no eres mía no eres de nadie»»". Se produjo un forcejeo, en el transcurso del cual la hoja del cuchillo se dobló y se separó del mango, por lo que el acusado, "manteniendo el ánimo de acabar con la vida de la mujer", la cogió por el cuello con las dos manos, mientras ella le suplicaba por su vida. Finalmente, atendiendo a las súplicas de ella, "el acusado cejó en su intención de acabar con su vida y sin cesar de sujetarla por el cuello, le dijo que permitiría que la curasen si decía que esas lesiones habían sido fruto de un intento de suicidio, amenazándola con que si le denunciaba a la policía, él iría a la cárcel pero al salir « voy por tu hija y a por ti», «ella va a pagar el problema» y «si dices otra cosa ya sabes quien lo va a pagar» ". Tras estos sucesos, salieron de la casa, dirigiéndose él a un bar próximo donde solicitó que llamaran al 112, porque una mujer había tratado de suicidarse. Al llegar la dotación de la policía, la mujer relató que su pareja había intentado matarla y solicitó protección para su hija.

La AP de Segovia - por Sentencia dictada el 16 de noviembre de 2017- condenó al acusado, en lo que aquí interesa, por un delito de lesiones causantes de deformidad, concurriendo la circunstancia agravante de discriminación por razones de género, señalando que la conducta quedaba "enmarcada dentro del ámbito de control y celos que se declara probado y la situación de dependencia de la víctima también descrita", lo que permi- 
te su aplicación. Contra esta resolución se interpuso recurso de apelación por el acusado, dictándose Sentencia por el TSJ de Castilla y León, que revocó, parcialmente, la SAP de Segovia, negando la apreciación de la agravante de actuar por razones de género, por considerar que no había quedado acreditado que "el actuar delictivo tuviera por móvil el desprecio o la discriminación de la víctima por el solo hecho de ser mujer o por el deseo de dominación machista que le atribuye la sala de instancia en el marco de esa relación de control y de celos que se dicen existentes; y no coincidimos con ella en que la sola personalidad del acusado que se desprende de la pericial practicada pueda derivarse esa intención de humillación y de ultraje que serían necesarios para apreciar la discutida agravante".

Con buen criterio, en la sentencia que resuelve el recurso de casación interpuesto por el Ministerio Fiscal contra la STSJ de Castilla y León, el TS subraya que, aunque, ciertamente, la acreditación de una determinada personalidad no puede justificar, por sí misma, en ningún caso, la aplicación de la agravante, en el relato fáctico consta que el acusado le quitó el móvil a la víctima al creer que pudiera estar comunicándose con otro hombre y que, en el curso de la agresión, manifestó "si no eres mía, no eres de nadie", hechos de los que "se desprende, en una valoración razonable, el intento de dominación del acusado sobre la víctima y su consideración de esa concreta mujer como un ser incapaz de tomar decisiones sobre los aspectos más personales e íntimos de su vida que pudieran merecer alguna clase de respeto". Por lo tanto, afirma el TS, "la dominación y el desprecio sobre la mujer, concretamente sobre la que recae la agresión, elementos necesarios para apreciar la agravante, resultan de las características de la conducta ejecutada, tal y como aparece descrita en los hechos probados" y estima, así, el recurso.

Resulta pertinente, en este punto, recordar que la SAP de A Coruña 198/2017, de 2 de mayo, según se expuso más atrás, en relación con idénticos hechos -recuérdese que el acusado, que mantenía una relación sentimental con la víctima, comenzó a ponerse celoso como consecuencia de la recepción por parte 
de esta de varios mensajes y a preguntarle por la procedencia de los mismos, para, finalmente, solicitarle la entrega del móvil y, ante su negativa, clavarle un cuchillo de cocina en el abdomen-, consideró inapreciable la circunstancia agravante de discriminación por razones de género.

En relación con el fundamento y los requisitos para la apreciación de la agravante objeto de estudio, la STS 420/2018, de 25 de septiembre, ratifica, exactamente, cuanto habían establecido los Tribunales penales -de forma prácticamente unánime- con anterioridad. En cuanto al fundamento, declara que el incremento de la pena se basa en la específica motivación del autor y confirma, a este respecto, lo establecido por la "jurisprudencia menor" acerca del sexo y el género, como motivos de discriminación, que darán lugar, respectivamente, a la apreciación de la circunstancia de discriminación por razón de sexo y a la de discriminación por razón de género, ambas previstas en el art. 22. $4^{\mathrm{a}} \mathrm{CP}$, esto es, que el sexo hace referencia a una característica biológica, mientras que el género se refiere a aspectos culturales relacionados con los papeles, comportamientos, actividades $\mathrm{y}$ atributos construidos socialmente, que una concreta sociedad considera propios de mujeres o de hombres ${ }^{24}$.

En cuanto a las condiciones que deben concurrir para su aplicación, corrobora que: a) el sujeto activo del delito debe ser un varón y el pasivo una mujer que se encuentre o se haya encontrado unida a aquel por una relación matrimonial o análoga ${ }^{25}$; b) que el sujeto activo ha de cometer el delito con el propósito de ejercer dominio sobre la mujer, es decir, de colocarla en un rol

24 Definición del término "género" ofrecida por el art. 3. C) del Convenio n. ${ }^{\circ}$ 210 del Consejo de Europa sobre prevención y lucha contra la violencia contra las mujeres y la violencia doméstica, aprobado en Estambul el 7 de abril de 2011.

25 Tomando como referencia el art. 1 de la LO 1/2004, de 28 de diciembre, de Medidas de Protección Integral contra la Violencia de Género y la jurisprudencia del TC recaída al respecto, considera que la agravante en cuestión tiene como finalidad la protección de las mujeres de determinadas conductas y en un ámbito determinado, como es el propio de las relaciones de pareja, aún sin convivencia. 
de inferioridad y subordinación en la relación; propósito cuya concurrencia debe desprenderse de elementos fácticos "debidamente acreditados por prueba válida, suficiente y racional y expresamente valorada en la sentencia".

2.2.2. STS (Sala de lo penal, secc. 1 ${ }^{a}$ ) 565/2018, de 19 de noviembre

Antes de cumplirse dos meses desde que el TS dictara la sentencia 420/2018, de 25 de septiembre, nos encontramos con la segunda resolución en la que vuelve a pronunciarse sobre esta cuestión, la STS 565/2018, de 19 de noviembre. También en esta ocasión el supuesto de hecho consiste en una tentativa de homicidio cometida por un varón contra la mujer con la que mantenía una relación análoga a la conyugal, con convivencia, desde hacía tres años, habiéndose declarado probado que "desde el inicio de la relación el acusado de forma reiterada golpeaba a Delfina, la amedrentaba, tiraba del pelo, la insultaba como manifestación de su dominio sobre ella". Asimismo, cuando ella trataba de romper la relación, "la conminaba a volver con él diciendo que iba a mostrar fotografías de ella desnuda a su madre, consiguiendo de este modo tener el control sobre ella". El acusado había sido condenado por la SAP de Madrid 211/2018, de 19 de marzo, como autor de un delito de maltrato habitual y de un delito de homicidio en grado de tentativa, concurriendo las circunstancias agravantes de parentesco y de discriminación por razones de género.

En el recurso de casación se alegan, entre otros motivos, la indebida aplicación de la agravante de discriminación por razones de género, así como la incompatibilidad entre dicha circunstancia y la agravante de parentesco. Al respecto, el TS confirma lo que ya era una postura prácticamente unánime entre la "jurisprudencia menor": que ambas agravantes poseen fundamentos distintos y que son, por lo tanto, compatibles. La novedad, sin embargo, se produce a la hora de definir la ratio de la agravante genérica de discriminación por razones de género. 
El TS afirma que el fundamento de la agravante de discriminación, por cualquiera de los motivos enumerados en el art. 22. $4^{\mathrm{a}} \mathrm{CP}$, reside en el mayor reproche penal que supone que el autor cometa los hechos motivado por sentirse superior a uno de los colectivos que en el mismo se citan y, además, como medio para demostrar a la víctima que la considera inferior ${ }^{26}$. En concreto, en relación con la discriminación por motivos de género, afirma que "se lleva a cabo una situación de subyugación del sujeto activo sobre el pasivo, pero sin concretarse de forma exclusiva el ámbito de aplicación de la agravante sólo a las relaciones de pareja o ex pareja, sino en cualquier ataque a la mujer con efectos de dominación, por el hecho de ser mujer. Esta es la verdadera significación de la agravante de género"27. Dicha circunstancia puede aplicarse conjuntamente con la de parentesco en las situaciones en las que exista o haya existido entre los sujetos del delito una relación matrimonial o análoga de carácter estable, pero ello "no excluye que la agravante de género pueda aplicarse también aisladamente si el ataque se hace a una mujer con la que el sujeto activo no tiene ninguna relación de pareja o ex pareja, pero se pueda desprender de la prueba practicada que se ha realizado el ilicito penal con actos que implican dominación del hombre hacia una mujer por el hecho de ser mujer" ${ }^{28}$. Con ello, el TS no solo modifica el criterio mantenido por las distintas Audiencias Provinciales y Tribunales Superiores de Justicia en relación con el ámbito de aplicación de la agravante objeto de estudio, sino que, en tan corto periodo de tiempo, corrige su propio posicionamiento, plasmado en la STS 420/2018, de 25 de septiembre.

2.2.3. STS (Sala de lo penal, secc. 19) 99/2019, de 26 de febrero

Pasados escasos tres meses desde la publicación de la STS 565/2018, de 19 de noviembre, el TS vuelve a cambiar de

26 La cursiva es nuestra.

27 La cursiva es nuestra.

28 La cursiva es nuestra. 
parecer en relación con los requisitos que deben concurrir para la apreciación de la agravante de discriminación por razones de género, afectando, esta vez, al fundamento que le había atribuido a la circunstancia.

En el caso en cuestión, según consta como probado en la sentencia de instancia, el acusado y la víctima habían sido pareja sentimental, sin convivencia, durante, aproximadamente, dos años, relación que ya había finalizado. El día 27 de noviembre de 2016, el acusado llamó a la mujer "y le propuso fumar un cigarro con él", lo que ella aceptó. Se trasladaron en el coche propiedad del acusado hasta una caseta de campo, pidiéndole él, durante el trayecto, "que le hiciera una felación, a lo que esta se negó", motivo por el cual "la cogió de la cabeza y la dirigió con fuerza hasta sus genitales y allí la obligó a hacerle una felación, a la vez que la golpeaba la cabeza, y le impedía que alzara la cabeza". Una vez que hubieron llegado a la mencionada caseta, el acusado la llamó "guarra, come pollas, hija de puta...", manifestando ella, entonces, que quería irse, a lo que él se opuso cogiéndola del pelo y del brazo, "arrastrándola hacía el interior de la caseta, donde tras lanzarla al suelo y propinarle patadas, le instó a que se quitara la ropa, a lo que ella se negó, y tras lanzarla sobre el sofá, le quitó el pijama, el procesado se quitó los pantalones y le quitó las bragas a Angelina, mientras ésta le pedía que no lo hiciera, diciéndole este «que haría lo que él quisiera, que para eso estaba y que no servía para otra cosa», momento en el que se puso encima de Angelina que estaba tumbada en el sofá y comenzó a penetrarla vaginalmente ${ }^{29}$ ". Posteriormente, el acusado la obligó a hacerle una felación, golpeándola en la cabeza y tirándole del pelo para doblegar su voluntad y, a continuación, la penetró, otra vez, por vía vaginal y, después, por vía anal, mientras la golpeaba en la cabeza, la espalda y los laterales del cuerpo, "tras lo cual la giró mientras él continuaba de pie y entonces eyaculó lanzándole el semen sobre la cara y al pecho a Angelina".

29 La cursiva es nuestra. 
La SAP de Valencia 167/2018, de 21 de marzo, condenó al acusado por un delito de agresión sexual en concurso medial con un delito de lesiones del art. 153.1 CP, no apreciando la concurrencia de la circunstancia agravante de discriminación por razones de género, por no considerar probado que el delito se cometiera con ánimo de dominación del hombre sobre la mujer. Contra esta sentencia se interpuso recurso de apelación, resuelto por la STSJ de la Comunidad de Valencia 91/2018, de 29 de junio, que consideró aplicable la circunstancia agravante de género en el delito de agresión sexual. Finalmente, esta última resolución se recurrió en casación por aplicación indebida de la agravante del art. 22. $4^{\text {a }} \mathrm{CP}$, recurso desestimado por la STS 99/2019, de 26 de febrero.

Según la STSJ de la Comunidad Valenciana 91/2018, de 26 de febrero, "dado que la Audiencia considera que concurre un delito del artículo 153 (delito que no es cuestionado por las partes) ello implica que las lesiones ocasionadas constituyen una manifestación de la discriminación, situación de desigualdad y las relaciones de poder entre el acusado y la víctima (...) por lo que si en las lesiones concurre esa situación de dominación, discriminación y desigualdad con mayor motivo en el delito de agresión sexual". Estas afirmaciones son aceptadas por la STS 99/2019, de 26 de febrero, a lo que añade que "la ley decide elevar la pena cuando reforma el artículo 153.1 del Código penal a conductas porque considera que son, objetivamente, prescindiendo de los motivos subjetivos del autor, tanto causa como expresión de la situación de desigualdad. El agresor puede no ser consciente de que tiene una conducta patriarcal y machista. Lo relevante es que los tipos de agresión en ese contexto relacional de agresor y víctima dan lugar a la discriminación y son, cuando se llevan a cabo, manifestación de tal situación". Por ello, concluye, siguiendo el criterio establecido, a este respecto, por la STS 677/2018, de 21 de diciembre, que el art. 153.1 CP no exige la constatación de un determinado propósito a modo de elemento subjetivo del injusto distinto del dolo. 
Atendiendo a lo anterior y sobre la base -según afirma la STS 99/2019, de 26 de febrero- de la identidad de fundamento existente entre los tipos afectados por la LO 1/2004, de 28 de diciembre, de Medidas de Protección Integral contra la Violencia de Género y la agravante de discriminación por razones de género, aun cuando el ámbito de aplicación de esta última no queda restringido al de las relaciones de pareja, considera que si tales tipos no exigen la concurrencia de un específico elemento subjetivo, dicho elemento subjetivo tampoco podrá reclamarse para la aplicación de la circunstancia objeto de estudio, cuyo efecto es "simplemente agravar la pena pero sin salir de la prevista para el tipo penal en el que se discute la aplicación de la agravante como genérica". Con ello, el TS abandona la tesis sostenida, de forma unánime, por "la jurisprudencia menor" y mantenida en sus SSTS 420/2018, de 25 de septiembre, y 565/2018, de 19 de noviembre, según la cual, para la aplicación de la agravante de discriminación por género, debía acreditarse que el sujeto activo cometió el delito con el propósito de ejercer su dominio, superioridad y control sobre la víctima por el hecho de ser mujer. La STS 99/2019, de 26 de febrero, por el contrario, le confiere a dicha circunstancia un fundamento puramente objetivo, ajeno al propósito del sujeto activo, fundamento que halla en la mayor gravedad del hecho cuando el mismo constituya una "manifestación de una grave y arraigada desigualdad"30. Así, afirma que "la interpretación de la previsión legal ha de enmarcarse en un objetivo corrector de la desigualdad o discriminación, ocurrida en un ámbito de relación autor-víctima, más específico que la diversidad de sexo biológico y más amplio que el del parentesco conyugal, y en el que aquella relación suponga un estatuto social, antes que jurídico, del que deriva una discriminación para la mujer relacionada socialmente con el autor del delito. Tal discriminación constituye el fundamento de la agravación cualificadora del artículo 153.1 cuando la mujer es o ha sido esposa del autor o ha estado ligada por relación de afectividad análoga, incluso sin convivencia. Para aplicar la agravante en casos ajenos

30 En negrita en el original. 
a esa relación de pareja habrá de exigirse al menos una asimetría en la relación entre varón-autor y mujer-víctima que sea reflejo de la discriminación que constituye el fundamento de la mayor sanción penal"31.

Sentado lo anterior, la STS 99/2019, de 26 de febrero, desestima el recurso de casación interpuesto por el acusado contra la STSJ de la Comunidad de Valencia, confirmando la concurrencia de la agravante de discriminación por género en el delito de agresión sexual, "pues es evidente que tal escenario y comportamiento implican objetivamente la situación de machismo origen de discriminación de la cual son los actos atribuidos al acusado, relación y asimétrico estatuto que sin duda les constaba y que resultaron funcionales para el objetivo delictivo ${ }^{32}$ ".

\subsubsection{Recapitulación}

A la vista de su última doctrina jurisprudencial, es posible afirmar que, durante este segundo periodo -desde la STS 420/2018, de 25 de septiembre hasta la STS 99/2019, de 26 de febrero-, la posición del TS, acerca de la agravante de discriminación por razones de género, ha cambiado de forma sustancial. Así, en relación con el ámbito de aplicación de dicha circunstancia, sigue siendo necesario que el sujeto activo del delito sea un varón y que el pasivo sea una mujer, pero ya no se exige que entre ambos exista o haya existido una relación matrimonial o análoga. Tampoco es preceptiva ya la concurrencia de un específico elemento subjetivo distinto del dolo, consistente en cometer el delito con el propósito de ejercer dominio sobre la mujer. Lo relevante es, prescindiendo de los motivos del autor, la existencia de una relación asimétrica entre el varón -sujeto activo- y la mujer -sujeto pasivo-, como manifestación objetiva de una grave y arraigada desigualdad.

En definitiva, se advierte la contradictoria aplicación de la agravante de discriminación por razones de género por parte

31 En negrita en el original.

32 La cursiva es nuestra. 
de las distintas Audiencias Provinciales y Tribunales Superiores de Justicia, así como trascendentales cambios de criterio por parte del TS en tan breve periodo de tiempo, lo que pone de relieve la necesidad de abordar, desde una perspectiva dogmática, el análisis de la circunstancia.

\section{La circunstancia agravante de discriminación por razones de género en la doctrina penal}

\subsection{Sobre la naturaleza de la circunstancia agravante de discriminación por razones de género}

Una vez expuesto el estado de la cuestión en la jurisprudencia en relación con la agravante de discriminación por razones de género, procederemos a analizar, de forma crítica y desde un punto de vista dogmático, las distintas cuestiones planteadas.

Excedería con mucho del objeto de esta investigación adentrarnos en la, sin duda, compleja y controvertida cuestión de la teoría General de las circunstancias modificativas de la responsabilidad criminal. Sin embargo, resulta imprescindible esbozar el planteamiento del que partimos a este respecto, pues ello va a condicionar nuestra posición sobre la naturaleza y el fundamento de la agravante objeto de estudio.

Las circunstancias modificativas son -sobre este extremo no existe duda- elementos accidentales del delito que modulan, aumentándola o disminuyéndola, la pena aparejada al mismo ${ }^{33}$. Sin embargo, no es pacífica la cuestión relativa a si las circunstancias poseen un fundamento dogmático - posición mayoritaria entre la doctrina ${ }^{34}$ - o político criminal y, por ende, si las mismas

33 Por todos, MIR PUIG, S.: Derecho Penal. Parte General, Barcelona, 2015, pp. 630 y 631 .

34 ALONSO ÁLAMO, M.: "Circunstancias del delito e inseguridad jurídica", en Circunstancias modificativas de la responsabilidad criminal. Cuadernos de Derecho Judicial, Madrid, 1995, pp. 49 y ss.; CEREZO MIR, J.: Curso de Derecho Penal español. Parte General, Madrid, 2004, p. 161; MUÑOZ CONDE, F. y GARCÍA ARÁN, M.: Derecho Penal. Parte General, Valen- 
deben ubicarse dentro la teoría del delito, afectando al injusto o a la culpabilidad, o, por el contrario, en la teoría de la pena ${ }^{35}$. A nuestro modo de ver, no es posible establecer, de forma categórica, esta dicotomía y, si bien en el catálogo de circunstancias modificativas de la responsabilidad criminal recogido en nuestro Código penal encontramos circunstancias que gradúan el injusto -como la agravante de ensañamiento- y circunstancias que gradúan la culpabilidad -como la atenuante de estados pasionales-, también existen otras cuyo fundamento no puede hallarse en la modificación de ninguna de estas dos categorías, sino, únicamente, en razones político-criminales, como sucede con las circunstancias atenuantes de confesión o de reparación del daño ${ }^{36}$.

Tradicionalmente, la doctrina mayoritaria, que -como hemos puesto de manifiesto- ubicaba las circunstancia modificativas de la responsabilidad criminal dentro la teoría del delito, ha venido distinguiendo, entre circunstancias subjetivas, por afectar a la culpabilidad, y circunstancias objetivas, por afectar a la antijuridicidad ${ }^{37}$. La razón para esta distinción ha querido

cia, 2015, p. 524. En este sentido, también, MIR PUIG, S.: Derecho Penal. Parte General, cit., p. 609, aunque reconoce que las atenuantes de confesión y de reparación del daño responden a finalidades político-criminales.

35 GONZÁLEZ CUSSAC, J. M.: Teoría general de las circunstancias modificativas de la responsabilidad criminal, Valencia, 1988, p. 87; id., "Presente y futuro de las circunstancias modificativas", en Circunstancias modificativas de la responsabilidad criminal. Cuadernos de Derecho judicial, Madrid, 1995, pp. 18 y ss.; COBO DEL ROSAL, M. y VIVES ANTÓN, T. S.: Derecho penal. Parte General, Valencia, 1999, pp. 878 y 879 . Véase, para un análisis en profundidad de estos posicionamientos doctrinales, SALINERO ALONSO, C.: Teoría general de las circunstancias modificativas de la responsabilidad criminal y artículo 66 del Código penal, Granada, 2000, pp. 64 y ss.

36 De esta opinión, QUINTERO OLIVARES, G.: Parte General del derecho penal, Navarra, 2010, p. 788; SALINERO ALONSO, C.: Teoría general de las circunstancias modificativas de la responsabilidad criminal y artículo 66 del Código penal, cit., pp. 72 y ss.

37 Véase, en profundidad, DÍEZ RIPOLLÉS, J. L.: "Naturaleza de las circunstancias modificativas, su referencia a los elementos del delito, y el artículo 60 del Código penal español", en Anuario de Derecho penal y Ciencias Penales, t. XXX, 1977, pp. 597 a 649. 
hallarse en el derogado artículo $60 \mathrm{TRCP}$-actual art. $65 \mathrm{CP}-$, entendiendo que el apartado 1 de dicho precepto hacía referencia a las circunstancias subjetivas, siendo estas, por tanto, incomunicables, mientras que el apartado 2 aludía a las objetivas, que serían, por el contrario, comunicables a los partícipes ${ }^{38}$. Esta clasificación tampoco es, a nuestro juicio, aceptable. Señala, y entendemos que con razón, DÍEZ RIPOLLÉS ${ }^{39}$, que el art. 60 TRCP -lo que es aplicable al vigente art. $65 \mathrm{CP}-$ no se encaminaba a formular una distinción entre las circunstancias de naturaleza objetiva y las de naturaleza subjetiva, sino que pretendía, únicamente, dar una norma clara a través de la cual no perdiera vigencia el principio de culpabilidad en relación con las circunstancias ${ }^{40}$. Pero, aun cuando quisiera hallarse en dicho precepto un criterio para catalogar las circunstancias modificativas, no es cierto que todas las que modulan la culpabilidad sean encuadrables en el apartado 1 y las que modulan el injusto lo sean en el apartado 2. Así, la circunstancia mixta de parentesco consiste en una "causa de naturaleza personal", pues se basa en la relación existente entre el sujeto activo y pasivo, por lo que, según el art. 65.1 CP agravará o atenuará la responsabilidad solo de aquellos en quienes concurra y, sin embargo, en nuestra opinión, es una circunstancia que afecta al injusto ${ }^{41}$.

38 Véanse, ALONSO ÁLAMO, M.: El sistema de circunstancias del delito, Valladolid, 1981, p. 345; BOLDOVA PASAMAR, M. A.: La comunicabilidad de las circunstancias y la participación delictiva, Madrid, 1995, p. 61.

39 Como señala DÍEZ RIPOLLÉS, J. L.: "Naturaleza de las circunstancias modificativas, su referencia a los elementos del delito, y el artículo 60 del Código penal español”, cit., p. 598, “con mayor o menor nitidez, según los autores, la mayoría de estos establecen una vinculación fija y unívoca entre estos tres problemas, en el sentido siguiente: Toda circunstancia de naturaleza subjetiva, se refiere a la culpabilidad, y en cuanto a la comunicabilidad acude al párrafo 1 del artículo 60 . A su vez, toda circunstancia de naturaleza objetiva, se refiere a la antijuridicidad, y es comunicable a tenor del párrafo 2 del artículo $60 "$.

40 De la misma opinión, QUINTERO OLIVARES, G.: Parte General del derecho penal, cit., pp. 787 a 789.

41 En este sentido, MIR PUIG, S.: Derecho Penal. Parte General, cit., p. 635, quien señala que dicha circunstancia "no modifica ni la imputabilidad ni la normal exigibilidad de la conducta". En sentido contrario, consideran que 
Por otra parte, es preciso advertir que, siguiendo a MIR PUIG, las circunstancias agravantes no pueden afectar a la culpabilidad, no pueden "«elevar» la imputación personal" este sentido, afirma que la imputación personal, entendida como condición de atribución del injusto penal, "puede no ser posible en absoluto e impedir la atribución, o no ser plenamente posible y permitir solo una atribución parcial. No puede, en cambio, crear un nuevo desvalor que no provenga ya del injusto penal, porque no puede más que atribuir el injusto penal que concurra"43. Lógicamente, no es esta la conclusión, como observa el autor, a la que conducen aquellas posiciones que conciben la culpabilidad como reprochabilidad de la actitud interna del sujeto $^{44}$. Sin embargo, no compartimos con MIR PUIG la afirmación de que todas las circunstancias agravantes deben aumentar lo injusto penal del hecho, pues, por ejemplo, la circunstancia agravante de reincidencia no halla, a nuestro juicio, en contra de su opinión, fundamento en una mayor gravedad del injusto, sino, exclusivamente, en razones político-criminales ${ }^{45}$.

En definitiva, antes de abordar el análisis de la circunstancia agravante de discriminación por razones de género, hemos de tener en cuenta, a nuestro modo de ver, lo siguiente:

afecta a la culpabilidad, ALONSO ÁLAMO, M.: El sistema de las circunstancias del delito. Estudio general, Valladolid, 1981, pp. 745 y ss.; BORJA JIMÉNEZ, E.: Las circunstancias atenuantes en el Ordenamiento Jurídico español, Valencia, 2001, pp. 219 a 22.

42 MIR PUIG, S.: Derecho Penal. Parte General, cit., p. 623.

43 MIR PUIG, S.: Derecho Penal. Parte General, cit., p. 622 (con cursiva en el original). A esta crítica se adhieren DOPICO GÓMEZ-ALLER, J.: "Delitos cometidos por motivos discriminatorios: una aproximación desde los criterios de legitimación de la pena", en Revista General de Derecho penal, $\mathrm{n}^{\circ} 4$, 2005, pp. 153 y 154 y REBOLLO VARGAS, R.: "La agravante de discriminación por razón de sexo y su fundamento (art. 22.4 del Código penal), en Revista General de Derecho penal, $\mathrm{n}^{\circ}$ 23, 2015, p. 21.

44 MIR PUIG, S.: Derecho Penal. Parte General, cit., p. 622, nota a pie ${ }^{\circ} 2$.

45 En este sentido, QUINTERO OLIVARES, G.: Parte General del derecho penal, cit., pp. 801 y 802 . 
1. No todas las circunstancias modificativas de la responsabilidad criminal tienen un fundamento dogmático, existiendo, en nuestro Código penal, circunstancias que afectan al injusto o a la culpabilidad, pero, también, otras que atienden a razones político-criminales.

2. No es posible establecer una vinculación entre circunstancias de carácter subjetivo, que afectan a la culpabilidad, y el art. 65. $1 \mathrm{CP}$ y circunstancias de carácter objetivo, que afectan al injusto, y el art. 65.2 $\mathrm{CP}^{46}$.

3. Las circunstancias agravantes no pueden incrementar la culpabilidad del sujeto.

\subsection{Sobre el fundamento de la circunstancia agravan- te de discriminación por razones de género}

Según hemos expuesto anteriormente, la "jurisprudencia menor" ha considerado, de forma unánime, que la agravante de discriminación por razones de género es una circunstancia de carácter subjetivo, que encuentra su fundamento en "la mayor culpabilidad del autor por la mayor reprochabilidad del móvil que le impulsa a cometer el delito". Esta tesis, que era compartida por el TS hasta su reciente STS 99/2019, de 26 de febrero, es también la sostenida por la doctrina mayoritaria, que, en idéntico sentido, se refiere al incremento de la culpabilidad que representa el "móvil abyecto que llevó al sujeto a actuar"47 o la "especial motivación, más reprochable, con la que pueden cometerse los delitos" 48 .

46 DÍEZ RIPOLLÉS, J. L.: "Naturaleza de las circunstancias modificativas, su referencia a los elementos del delito, y el artículo 60 del Código penal español", cit., p. 644; SALINERO ALONSO, C.: Teoría general de las circunstancias modificativas de la responsabilidad criminal y artículo $66 \mathrm{del}$ Código penal, cit., pp. 59 y ss.

47 COBO Del ROSAL, M. y VIVES ANTÓn, T. S.: Derecho penal. Parte General, cit., p. 897.

48 CEREZO MIR, J.: Curso de Derecho Penal español. Parte General, III, Madrid, 2004, p. 161. En el mismo sentido, MUÑOZ CONDE, F. y GARCÍA ARÁN, M.: Derecho penal. Parte General, Valencia, 2015, p. 524; 
Como puede observarse, tales posicionamientos siguen la tesis clásica que vinculaba la naturaleza subjetiva de las circunstancias a la graduación de la culpabilidad y, a su vez, al art. 65.1 $\mathrm{CP}$; vinculación que, por las razones indicadas anteriormente, no puede admitirse. Pero, además, sostienen que la agravante objeto de estudio incrementa la culpabilidad del autor a causa de la mayor reprochabilidad del móvil que le condujo a cometer el delito, argumento que también hemos rechazado previamente.

Descartado, por lo tanto, que el fundamento de la agravante de discriminación por razones de género haya de buscarse en la categoría de la culpabilidad, es preciso atender a la tesis propuesta por MIR PUIG ${ }^{49}$, quien considera que nos encontramos ante una circunstancia subjetiva, empleando este adjetivo, no en el sentido tradicional -que identificaba circunstancia subjetiva con circunstancia moduladora de la culpabilidad-, sino para expresar que la circunstancia objeto de estudio incrementa el injusto subjetivo ${ }^{50}$. En opinión del citado autor, este incremento del injusto subjetivo del hecho se basa en "una motivación particularmente indeseable", que "añade al injusto propio del delito realizado la negación del principio de igualdad consagrado en la Constitución" 51 .

ALONSO ÁLAMO, M.: "La circunstancia agravante de discriminación", en La ciencia del Derecho penal ante el nuevo siglo. L-H al Prof. Dr. D. José Cerezo Mir, Madrid, 2002, p. 538.

49 MIR PUIG, S.: Derecho Penal. Parte General, cit., p. 623. En el mismo sentido, MAQUEDA ABREU, M. L.: “¿Necesitan un móvil discriminatorio las agravantes de sexo/género del art. 22.4 CP?”, en SILVA SÁNCHEZ, J. M., QUERALT JIMÉNEZ, J. J., CORCOY BIDASOLO, M. y CASTIÑEIRA PALOU, M. T.: Estudios de Derecho penal. Homenaje al profesor Santiago Mir Puig, Montevideo, 2017, p. 710.

50 Por el contrario, según el autor, son objetivas las agravantes que aumentan la gravedad del injusto objetivo.

51 MIR PUIG, S.: Derecho Penal. Parte General, cit., p. 623 (en cursiva en el original). En el mismo sentido, SALINERO ALONSO, C.: Teoría general de las circunstancias modificativas de la responsabilidad criminal y artículo 66 del Código penal, cit., p. 75, quien afirma que "el desvalor (subjetivo) de la acción, fuera del tipo - circunstancias-, puede verse constituido por determinados móviles o intenciones que supongan su aumento (...)", como es el caso de los móviles discriminatorios. 
Sin embargo, la admisión de este argumento supondría fundamentar el aumento de la pena que deriva de la aplicación de la agravante de discriminación por razones de género en la concurrencia en el sujeto activo de una determinada ideología, en este caso, machista -que le conduce a su comisión-, lo que implicaría, en consecuencia, admitir que la ratio de la agravante se encuentra en la personalidad del reo, en los móviles que dirigen su actuación, situándonos ante la manifestación de un inconstitucional Derecho penal de autor ${ }^{52}$.

Por tales razones, y pese a reconocer, con LAURENZO $\mathrm{COPELLO}^{53}$, que el tenor literal de la formulación legal -que hace expresa referencia a los "motivos"-y la intención del propio legislador, probablemente, se ajusten mejor a una fundamentación subjetiva de la agravante, donde el plus de gravedad se encuentre en la motivación del autor, consideramos que es posible hallar una justificación objetiva a la previsión de la circunstancia de discriminación por razones de género, que se acomode a los presupuestos de un Derecho penal del hecho propio de un sistema democrático. La citada autora es una de las máximas representante de las tesis que sitúan la ratio de la circunstancia objeto de estudio en un desvalor adicional del resultado. Así, sostiene que, desde esta perspectiva, "la mayor penalidad se ex-

52 De esta opinión, GÓMEZ-ALLER, J.: "Delitos cometidos por motivos discriminatorios: una aproximación desde los criterios de legitimación de la pena", cit., p. 152, quien, de forma gráfica, señala que "en nuestros modelos constitucionales sería ilegítima una norma como « ¡no lo guíes por motivos racistas! », que sería la única que podría explicar la diferencia subjetiva-motivacional entre un delito de lesiones «motivado» por ideas racistas, xenófobas, etc., y otro carente de dicha motivación". En el mismo sentido, HORTAL IBARRA, J. C.: "La circunstancia agravante por motivos racistas o discriminatorios (art. 22. $4^{\text {a }} \mathrm{CP}$ ): una propuesta restrictiva de interpretación", en Cuadernos de Política Criminal, n 108, 2012, pp. 43 y ss. En relación con las dificultades probatorias de las motivaciones, véase, LANDA GOROSTIZA, J. M.: La intervención penal frente a la xenofobia: problemática general con especial referencia al "delito de provocación" del artículo 510 del Código Penal, Bilbao, 1999, p. 212.

53 LAURENZO COPELLO, P.: "La discriminación en el Código penal de 1995”, en Estudios penales y Criminológicos, nº 19, 1996, p. 247. 
plicaría porque, además de lesionarse el bien jurídico protegido por el delito cometido, se afecta a otro bien adicional, concretamente, el derecho del sujeto pasivo a ser tratado como un ser humano igual a cualquier otro" $54 \mathrm{y}$ critica, entendemos que con razón, la redacción actual de la agravante, proponiendo, como alternativa, la de "cometer el delito contra determinadas personas por razón de su ideología, etc...", que, en el lugar de poner el acento sobre los motivos del autor, remarca los efectos sobre la víctima ${ }^{55}$.

Sin embargo, pese a que compartimos con la autora la caracterización objetiva de la circunstancia agravante de discriminación por razones de género, consideramos que no es correcto, desde un punto de vista dogmático, definir este "bien adicional" como el "derecho a la igualdad", pues no es posible identificar un derecho subjetivo con un bien jurídico penalmente protegido o protegible ${ }^{56}$. Se trataría, entendemos, en todo caso, de la lesión a un valor ideal, a un interés, que, en este caso, vendría representado por "la igualdad".

Hecha esta matización, entendemos que el fundamento de la circunstancia agravante de discriminación por razones de género sí se encuentra en el plus de desvalor de resultado -que se añade al propio del delito cometido- que supone el atentado a

54 LAURENZO COPELlO, P.: "La discriminación en el Código penal de 1995”, cit., p. 281. En este sentido, GARCÍA ÁlVAREZ, P.: El Derecho penal y la discriminación, Valencia, 2003, p. 289.

55 LAURENZO COPELlO, P.: "La discriminación en el Código penal de 1995”, cit., p. 281, nota $n^{\circ} 118$. En este sentido, REBOLLO VARGAS, R.: "La agravante de discriminación por razón de sexo y su fundamento (art. 22.4 del Código penal)", cit. p. 25; MARÍN DE ESPINOSA CEBALLOS, E. B.: "La agravante de discriminación por razones de género (art. 22. 4 CP)", en Revista electrónica de ciencia penal y criminología, $\mathrm{n}^{\circ} 20,2018$, pp. 4 y ss., quien defiende que el incremento de la pena se fundamenta en la vulneración del derecho fundamental a la igualdad ante la ley, "por dar a la víctima un trato completamente arbitrario e indigno por su mera pertenencia o vinculación a un colectivo discriminado".

56 Véase, SAN MILLÁN FERNÁNDEZ, B.: "Reflexiones críticas en torno al delito de coacciones a la huelga", en Revista de Derecho y Proceso penal, $\mathrm{n}^{\circ}$ 52,2018, pp. 23 y 24. 
"la igualdad", como valor merecedor de tutela penal ${ }^{57}$. El valor "igualdad" -valor superior de nuestro Ordenamiento Jurídico, según el art. 1.1 CE- se lesiona, como afirma DE LA CUESTA $\mathrm{AGUADO}^{58}$, cuando el delito "se aprovecha o incide en procesos de victimización social que sufren las mujeres en nuestra sociedad por el hecho de serlo"59. Esta situación de victimización social de la mujer, que la sitúa, por el mero hecho de serlo, en una posición de inferioridad con respecto del hombre, tiene hondas raíces históricas - por lo demás, sobradamente conocidas-y ha propiciado, desde antiguo, el ejercicio de violencia contra las mujeres -fundamentalmente en el seno familiar, aunque no solo,

57 Interesante resulta la posición sostenida -si bien referida a los delitos xenófobos-por un sector doctrinal que considera que el interés lesionado por la agresión de significación xenófoba, que justifica una agravación de la responsabilidad penal, tiene un carácter supraindividual o colectivo, pues menoscaba las expectativas de indemnidad de ciertos grupos de personas, que las amenaza con la continuidad del estado de inseguridad en el que se encuentran o "situación crítica" (LANDA GOROSTIZA, J. M.: La intervención penal frente a la xenofobia: problemática general con especial referencia al "delito de provocación" del artículo 510 del Código Penal, cit., pp. 355 y ss. En este sentido, aunque con matices, DOPICO GÓMEZ-ALLER, J.: "Delitos cometidos por motivos discriminatorios: una aproximación desde los criterios de legitimación de la pena", cit. pp. 166 y ss.).

58 DE LA CUESTA AGUADO, P. M.: "Machismo y violencia. El concepto de «(violencia de género penal»", en CASTILLEJO MANZANARES, R. (dir.), Violencia de género y Justicia, Santiago de Compostela, 2013, pp. 63 y 64. No faltan, no obstante, quienes consideran que la introducción de esta circunstancia agravante en el art. 22. $4^{\mathrm{a}} \mathrm{CP}$ obedece a razones puramente simbólicas. En este sentido, véanse, AGUILAR CÁRCELES, M. M.: "Proposición para delinquir. Agravante de discriminación en razón del género y agravante de reincidencia. El concepto de discapacidad y discapacidad necesitada de especial protección", en MORILLAS CUEVA, L., (dir.), Estudios sobre el Código penal reformado (Leyes Orgánicas 1/2015 y 2/2015), Madrid, 2015, p. 63 y BORJA JIMÉNEZ, E.: "La circunstancia agravante de discriminación del art. 22. $4^{\text {a" }}$, cit., p. 119.

59 Proceso de victimización social que, según aclara la citada autora, no debe confundirse con el proceso individualizado de victimización primaria que padece la mujer víctima de violencia de género. Ambos procesos de victimización concurren en tales supuestos, lo que explica la mayor gravedad de la respuesta penal (DE LA CUESTA AGUADO, P. M.: "Machismo y violencia. El concepto de «(violencia de género penal»”, cit. pp. 63 y 64). 
como consecuencia de la asignación a estas de determinados ro${ }^{l e s}{ }^{60}$. Tanto es así que, hasta fechas relativamente cercanas, esta violencia era silenciada, normalizada, cuando no justificada. Cierto es, como señala la citada autora, que "la discriminación y minusvaloración del sexo femenino es cada vez menos grosera, menos explícita, pero sus consecuencias siguen manifestándose en todos los órdenes de la vida: formas de educación, desigual valoración de conductas idénticas o distribución desigual de poder" ${ }^{\prime \prime}$. No se trata, por lo tanto, de una discriminación basada en la condición biológica, masculina o femenina, es decir, en el sexo del sujeto pasivo, sino en el papel que socialmente se le asigna en atención a esa condición ${ }^{62}$. El género es, en consecuencia, una construcción sociocultural ${ }^{63} \mathrm{y}$ así lo ha considerado el Convenio n. ${ }^{\circ} 210$ del Consejo de Europa sobre Prevención y Lucha contra la Violencia contra las Mujeres y la Violencia Doméstica, aprobado en Estambul el 7 de abril de 2011, del que trae causa, como expresamente declara el Preámbulo de la LO $1 / 2015$, la reforma de la agravante del art. 22. $4^{\mathrm{a}} \mathrm{CP}^{64}$.

60 Véase, a este respecto FARALDO CABANA, P.: "Razones para la introducción de la perspectiva de género en Derecho penal a través de la Ley Orgánica 1/2004, de 28 de diciembre, sobre medidas de protección integral contra la violencia de género", en Revista Penal, n 17, 2006, p. 86.

61 DE LA CUESTA AGUADO, P. M.: "Machismo y violencia. El concepto de «(violencia de género penal»»", cit. p. 64 .

62 En sentido contrario, MAQUEDA ABREU considera que la agravante de discriminación por razón de sexo, prevista con anterioridad a la reforma operada por la LO 1/2015 en el art. 22. 4 ${ }^{\mathrm{a}} \mathrm{CP}$, “cumple sobradamente con el objetivo de identificar a las mujeres como grupo discriminado. Y es que, en este contexto, el sexo no opera como una realidad biológica, sino que lleva implícita una referencia al género que es el que, gracias a su poder de construir y de asignar espacios, sitúa a las mujeres en esa posición subalterna, de subordinación social, por lo que podría decirse que juntos, sexo y género están expresando lo mismo” (MAQUEDA ABREU, M. L.: “¿Necesitan un móvil discriminatorio las agravantes de sexo/género del art. 22.4 CP?”, cit., p. 713).

63 Diccionario de la RAE (23 edición), acepción tercera del término "género".

64 "El género, entendido de conformidad con el Convenio n. ${ }^{\circ} 210$ del Consejo de Europa sobre prevención y lucha contra la violencia contra las mujeres y la violencia doméstica, aprobado en Estambul por el Comité de Ministros del Consejo de Europa el 7 de abril de 2011, como «los papeles, comporta- 
De este modo, la agravante objeto de estudio será de aplicación cuando el delito cometido constituya una manifestación de discriminación a la víctima por el hecho de ser mujer o, dicho de otra forma, cuando constituya una manifestación de la posición de superioridad que al hombre -sujeto activo- le otorga la situación de victimización social que la mujer - sujeto pasivopadece, situación de la que su conducta delictiva se aprovecha y en la que repercute. De ello se deriva, lógicamente, tal como han establecido tanto la "jurisprudencia menor" como el TS, que el sujeto pasivo del delito ha de ser, para que pueda concurrir la agravante de discriminación por razones de género, una mujer $^{65}$, pues, nuevamente con DE LA CUESTA AGUADO ${ }^{66}$, la violencia ejercida por una mujer contra un hombre no obedece a "razones de género" en el sentido indicado, porque "no se debe a la diferente posición que, como consecuencia de ideologías discriminatorias que legitiman una posición de privilegio, dominio y posición preeminente de un sexo sobre otro, por la evidente razón de que, en esta sociedad, quienes ocupan esa posición socialmente privilegiada son los hombres".

Como hemos puesto de relieve, también el TS, en su última sentencia sobre el particular - STS 99/2019, de 26 de febrero-, confiere un fundamento objetivo a la agravante de discriminación por razones de género, basado en la mayor gravedad del hecho cuando el mismo constituya manifestación de la situación de desigualdad entre hombres y mujeres. Sin embargo, no podemos compartir el razonamiento a través del cual se alcanza esta

mientos o actividades y atribuciones socialmente construidos que una sociedad concreta considera propios de mujeres o de hombres», puede constituir un fundamento de acciones discriminatorias diferente del que abarca la referencia al sexo".

65 En contra, OREJÓN SÁNCHEZ DE LAS HEREAS, N.: "La agravante genérica de discriminación por razones de género", Tesis Doctoral dirigida por Paz Lloria García, Valencia, 2018, p. 149. Disponible en http://roderic. uv.es/bitstream $/$ handle $/ 10550 / 66676 /$ tesis.pdf? sequence $=1 \&$ is Allowed=y [fecha de última consulta: 13 de febrero de 2019].

66 DE LA CUESTA AGUADO, P. M.: "Violencia de género: heteroprotección y autoprotección" (pendiente de publicación). 
conclusión. Entendemos que no es posible afirmar que exista una identidad de fundamento entre los tipos afectados por la LO de Medidas de Protección Integral Contra la Violencia de Género y la agravante de discriminación por razones de género, pues, contrariamente a lo que sostiene la citada sentencia, dicha Ley no ha tenido en cuenta la discriminación por razón de género en la configuración de tales tipos. Efectivamente, las agravaciones que introduce la "Ley Integral" no se construyen -como hubiera sido deseable- en torno a la ejecución del hecho delictivo como manifestación de discriminación por género, sino en torno al sexo del sujeto pasivo del mismo. Por lo tanto, se trata de delitos de aplicación automática cuando la víctima sea la esposa, exesposa o mujer que esté o haya estado ligada al autor por una análoga relación de afectividad, aun sin convivencia, tal y como ha confirmado la STS 677/2018, de 21 de diciembre, zanjando, así, la discusión acerca de la exigencia de un específico elemento subjetivo del injusto, concretado en el denominado "animus machista" ${ }^{67}$. Por el contrario, la agravante que ahora nos ocupa hace referencia a la "discriminación por razones de género" -elemento que no aparece en los tipos reformados por la "Ley Integral"-, lo que supone, por más que a la misma se le haya otorgado una fundamentación objetiva, que no es de aplicación automática, siempre que el sujeto activo del delito sea un varón y el pasivo una mujer, sino que será preciso constatar que, en el caso concreto, la actuación del hombre constituye una manifestación de discriminación en el sentido anteriormente indicado.

\subsection{Sobre la comunicabilidad de la circunstancia de discriminación por razones de género}

De lo anterior se deriva, inmediatamente, el régimen de comunicabilidad de dicha circunstancia a los partícipes en el delito de que se trate. Según la doctrina mayoritaria, que considera que el mayor desvalor que justifica la aplicación de la circunstancia se halla en los móviles del autor, se trata de una

67 Véase, ROIG TORRES, M.: "La delimitación de la «violencia de género»: un concepto espinoso", en Estudios Penales y Criminológicos, vol. 32, 2012, pp. 273 y ss. 
“causa de naturaleza personal" y, por lo tanto, solo agravará la responsabilidad de aquellos en quienes concurra (art. 65.1 CP) ${ }^{68}$. Sin embargo, según la tesis aquí sostenida, el fundamento de la agravante objeto de estudio no se encuentra en la motivación del sujeto activo del delito, sino en un mayor desvalor del resultado, lo que nos traslada al ámbito de la "ejecución material del hecho" ${ }^{69}$ (art. 65.2 CP). En consecuencia, a nuestro juicio, la agravante de discriminación por razones de género es una circunstancia comunicable, que agravará la responsabilidad de quienes hayan tenido conocimiento de ella en el momento de la acción o de su cooperación al delito. Dicho de otro modo, y por tomar alguno de los casos expuestos al analizar la jurisprudencia sobre la materia, si un sujeto mata a su mujer porque esta se niega a entregarle su teléfono móvil para poder controlar sus comunicaciones o porque no acepta la ruptura de la relación que mantenía con ella, al partícipe en este hecho que conociera estos extremos y que, por lo tanto, conocía que el hecho constituía una manifestación de dominación de ese hombre sobre esa mujer, le será de aplicación la agravante de discriminación por razones de género, resultando indiferente si su motivación para contribuir en el delito fue, en efecto, su convencimiento de la prevalencia del varón respecto de la mujer o si fue, por ejemplo, meramente económica.

\subsection{Sobre la compatibilidad de la circunstancia de discriminación por razones de género con la agravante de parentesco}

Como hemos expuesto a lo largo de esta investigación, la "jurisprudencia menor", de forma unánime, había estableci-

68 CEREZO MIR, J.: Curso de Derecho Penal español. Parte General, III, cit., p, 161. En el mismo sentido, MUÑOZ CONDE, F. y GARCÍA ARÁN, M.: Derecho penal. Parte General, cit., p. 524; ALONSO ÁLAMO, M.: "La circunstancia agravante de discriminación", cit., p. 538; PUENTE SEGURA, L.: Circunstancias eximentes, atenuantes y agravantes de la responsabilidad criminal, Madrid, 1997, p. 509.

69 LAURENZO COPELLO, P.: "La discriminación en el Código penal de 1995 ", cit., p. 285. 
do que la agravante de discriminación por razones de género era de aplicación, únicamente, cuando el sujeto pasivo del delito en cuestión fuera la esposa, exesposa o mujer que estuviera o hubiera estado ligada al autor por una relación análoga de afectividad, aún sin convivencia. Este requisito fue confirmado por la primera sentencia del TS sobre el particular -STS 420/2018, de 25 de septiembre-, aunque, posteriormente, modificado por la STS 565/2018, de 19 de noviembre. Ello suponía, según ya hemos tenido oportunidad de apuntar, que en los supuestos en los que se ha planteado la concurrencia de la agravante de discriminación por razones de género, era, a su vez, susceptible de aplicación la agravante de parentesco. Los Tribunales penales, también lo hemos puesto de manifiesto, han declarado la compatibilidad de ambas circunstancias, afirmando que poseen fundamentos distintos: la de parentesco, la existencia de una relación sentimental, presente o pasada, entre los sujetos del delito; la de discriminación, la existencia de una motivación específica en el sujeto activo, consistente en el propósito o intención de ejercer su dominio sobre la víctima por el hecho de ser mujer.

Sin embargo, aunque, a nuestro modo de ver, la ratio de estas dos circunstancias es, ciertamente, distinta, lo cierto es que tanto la "jurisprudencia menor" como el TS, en su sentencia de 25 de septiembre, no las habían atribuido ese -pretendido- diverso fundamento. En efecto, exigir que la mujer, sujeto pasivo del delito, sea esposa, exesposa, pareja o expareja del autor, para la aplicación de la agravante de discriminación por razones de género, supondría establecer la justificación del incremento de la pena en la discriminación a la mujer en el contexto de las relaciones de pareja -y solo en tal contexto-. El fundamento de la agravante, por lo tanto, se había situado no solo en la discriminación a la mujer -0 , mejor dicho, en la discriminación a la mujer por el solo hecho de serlo- sino, también, en la existencia de una relación entre esta y el autor del delito. De este modo, a nuestro juicio, la aplicación de la circunstancia de parentesco como agravante en base a la existencia, presente o pasada, de una relación de esas características entre autor y víctima, junto 
con la agravante de género, siendo uno de los requisitos exigidos para la apreciación de esta última, precisamente, esta misma relación, implica tener en cuenta doblemente dicha circunstancia para agravar la pena, incurriendo en un bis in ídem prohibido.

En la STS 565/2018, de 19 de noviembre, el TS cambia de criterio y establece, expresamente, que el ámbito de aplicación de la agravante de discriminación por razones de género no se limita al de los cónyuges, excónyuges, parejas o exparejas sentimentales. En consecuencia, la relación de pareja entre el sujeto activo y pasivo del delito deja de ser condición indispensable para la concurrencia de la circunstancia objeto de estudio, que halla, ahora sí, su justificación, exclusivamente, en la existencia de un ataque a la mujer por el hecho de ser mujer. Quedan, de este modo, claramente delimitados los diversos fundamentos de las dos agravantes. Por lo tanto, en aquellos casos en los que el delito cometido sea expresión de la superioridad que al hombre - sujeto activo- le otorga la situación de victimización social que la mujer -sujeto pasivo- padece, concurrirá la agravante de discriminación por razones de género y si, además, existe o ha existido una relación matrimonial o análoga entre los sujetos, dicha relación podrá dar lugar a la aplicación de la agravante de parentesco, sin que ello suponga una doble valoración de esta circunstancia.

Pero, en la resolución acabada de citar, el TS no solo corrige su anterior postura $-\mathrm{y}$ la de la "jurisprudencia menor"-, sino que, además, acoge un concepto de violencia de género más amplio que el ofrecido por el art. 1 de la LO 1/2004, de 28 de diciembre, de Medidas de Protección Integral contra la Violencia de Género, que, como es sabido, constriñe tal concepto a la violencia - o, por mejor decir, a algunos actos de violencia, los menos graves- ejercida contra la mujer en el contexto de las relaciones de pareja ${ }^{70}$. Eliminando el requisito de la existencia

70 Véase, ACALE SÁNCHEZ, M.: "Análisis del Código penal en materia de violencia de género contra las mujeres desde una perspectiva transversal", en $R E D U R, \mathrm{n}^{\circ} 7,2009$, pp. 37 y ss. 
de un vínculo matrimonial o de noviazgo entre los sujetos del delito, parece que el TS ha decidido atender, finalmente, a las definiciones establecidas por el Convenio de Estambul, el cual, al menos en teoría -pues así lo declara el Preámbulo de la LO 1/2015-, se encuentra en el origen de la introducción de "las razones de género" como causa de discriminación en la agravante del art. 22. 4 $4^{\mathrm{a}} \mathrm{CP}$ y que distingue, de forma clara, entre la "violencia doméstica" y "la violencia de género" "71, conceptos que la "Ley Integral" mezcla ${ }^{72}$.

La agravante de discriminación por razones de género, así entendida, vendrá a solucionar algunas de las disfunciones que, como ha puesto de manifiesto buena parte de la doctrina especializada, generó la entrada en vigor de la denominada "Ley Integral" "73. En primer lugar, como ya apuntábamos, esta Ley contiene una definición de la violencia de género incompleta, pues excluye de su ámbito de protección a las mujeres que no estén o no hayan estado vinculadas con el autor por una relación

71 Así, por "«violencia doméstica» se entenderán todos los actos de violencia física, sexual, psicológica o económica que se producen en la familia o en el hogar o entre cónyuges o parejas de hecho antiguos o actuales, independientemente de que el autor del delito comparta o haya compartido el mismo domicilio que la víctima" (art. 3. b.), mientras que por "«violencia contra las mujeres por razones de género») se entenderá toda violencia contra una mujer porque es una mujer o que afecte a las mujeres de manera desproporcionada" (art. 3. d.).

72 Véase, sobre el concepto erróneo de violencia de género recogido en la LO 1/2004, de 28 de diciembre, MARÍN DE ESPINOSA CEBALLOS, E.: "El marco normativo de la violencia de género: un estudio de derecho comparado acerca de las leyes de segunda generación y de la ley integral española", en Revista de Derecho Penal y Criminología, n 17, p. 110.

73 La incorporación del género como causa de discriminación en la agravante genérica del art. 22. $4^{\mathrm{a}} \mathrm{CP}$, como alternativa a los tipos que prevén agravaciones por el sexo y la relación existente entre los sujetos del delito, ya había sido demandada por la doctrina especializada con anterioridad a la reforma penal de 2015. Véanse, ACALE SÁNCHEZ, M.: La discriminación hacia la mujer por razón de género en el Código penal, Madrid, 2006, p. 63; COMAS D" ARGEMIR I CENDRA, M. D.: "La ley integral contra la violencia de género: nuevas vías de solución", en BOLDOVA PASAMAR, M. A. y RUEDA MARTÍN, M. A. (coords.), La reforma penal en torno a la violencia doméstica y de género, Barcelona, 2006, p. 35. 
matrimonial o análoga de afectividad ${ }^{74}$. Con esta nueva interpretación, la agravante objeto de estudio permitirá incrementar la pena por el mayor desvalor de resultado que entraña la comisión de un delito cuando el mismo constituya una manifestación de discriminación a la mujer, en los términos anteriormente indicados, con independencia de la relación que la misma -sujeto pasivo- tenga con el varón -sujeto activo-. Pensemos, y solo por citar algunos ejemplos de delitos que, por sus propios requisitos típicos, no pueden tener lugar en el contexto de las relaciones sentimentales, como el mobbing o el acoso sexual, o que no tienen por qué tener lugar en dicho contexto, como el stalking, y en cuya comisión no es -más bien todo lo contrario- infrecuente que concurran "las razones de género".

En segundo lugar, la "Ley Integral" solo afectó a la calificación jurídica y a la gravedad de la pena de determinadas conductas, concretamente las constitutivas de las faltas -ahora de delitos leves- de lesiones, maltrato de obra, amenazas y coacciones leves y del delito de lesiones del tipo básico del art. 147.1 $\mathrm{CP}$, pero no, de forma inexplicable, a los delitos más graves que pueden cometerse contra una mujer $-\mathrm{y}$ que, de hecho, se comenten con frecuencia en este contexto- que esté o haya estado ligada al autor por matrimonio o análoga relación de afectividad, como son los delitos contra la vida, las lesiones específicas de los arts. 149 y $150 \mathrm{CP}$, las amenazas y coacciones graves, el aborto y las lesiones al feto, las detenciones ilegales o los delitos contra la libertad sexual ${ }^{75}$. Ahora, a tales delitos, cuando puedan

74 En este sentido, RAMON RIBAS, E.: Violencia de género y violencia doméstica, Valencia, 2008, pp. 91 y ss.; DE LA CUESTA AGUADO, P. M.: "Machismo y violencia. El concepto de 〈〈violencia de género penal»», cit. pp. 60 y 64; MANJÓN-CABEZA OLMEDA, A.: "Violencia de género y doméstica", en ÁlVAREZ GARCÍA, F. J. (Dir.), Derecho Penal español. Parte Especial, t. I, Valencia, 2011, pp. 491 y 492; MARÍN DE ESPINOSA CEBALLOS, E. B.: "La agravante de discriminación por razones de género (art. 22. 4 CP)", cit., p. 13; VILLACAMPA ESTIARTE C.: "Pacto de estado en materia de violencia de género: ¿más de lo mismo?", en Revista electrónica de Ciencia Penal y Criminología, nº 20, 2018, pp. 15 a 17.

75 En sentido crítico, MANJÓN-CABEZA OLMEDA, A.: "Violencia de género y doméstica", cit., pp. 490 y 491, quien señala, con razón, que "la selec- 
ser calificados como atentados de género, les será de aplicación, por tratarse de una circunstancia modificativa genérica, la agravante de discriminación, mantenga la víctima -o haya mantenido- o no una relación con el sujeto activo ${ }^{76}$. Si, además, dicha relación existe - $\mathrm{o}$ ha existido-, podrá aplicarse, por tratarse, según se ha expuesto, de circunstancias compatibles, la agravante de parentesco.

Finalmente, la supresión del requisito de la relación matrimonial o análoga entre los sujetos permite aplicar la circunstancia agravante de discriminación por razones de género al delito de malos tratos habituales del art. 173.2 CP, tipo penal que tampoco había sido modificado por la "Ley Integral" para introducir una reacción punitiva más severa en el caso de que el sujeto pasivo fuera mujer - unida al autor por los vínculos de matrimonio o relación análoga, presente o pasada, típicamente exigidos-, lo que resulta, cuando menos, contradictorio con el que se declara como objeto de dicha norma (art.1), a saber el de actuar contra la violencia que, como manifestación la situación de desigualdad y las relaciones de poder de los hombres sobre las mujeres, se ejerce sobre estas en el contexto de las relaciones de pareja ${ }^{77}$. Con la nueva interpretación dada por el TS, la agravante de discriminación por género podrá concurrir cuando el sujeto pasivo del delito de maltrato habitual sea o haya sido

ción de las conductas que se agravan por razón de género no cuadra con la declaración que se hace en la Exposición de Motivos" de la LO 1/2004, de 28 de diciembre, de que la violencia de género es el símbolo más brutal de desigualdad.

76 Este era uno de los motivos por los que ACALE SÁNCHEZ, con anterioridad a la reforma operada por la LO 1/2015, de 30 de marzo, abogada por la inclusión de los motivos de género en la agravante genérica de discriminación del art. 22. $4^{\mathrm{a}}$ CP (ACALE SÁNCHEZ, M.: "Análisis del Código penal en materia de violencia de género contra las mujeres desde una perspectiva transversal", en VILLACAMPA ESTIARTE, C., Violencia de género y sistema penal, Valencia, 2008, p. 158).

77 De forma errónea, la SAP de Cantabria 204/2018, de 7 de junio, excluía la posibilidad de aplicar la agravante de discriminación por razones de género al art. 173.2 CP sobre la base de que "las razones de género forman parte de la descripción típica”. 
la esposa del autor o se encuentre o haya encontrado ligada a él por una análoga relación de afectividad, aun sin convivencia, siempre que el delito se haya cometido como expresión de superioridad de este sobre aquella. En efecto, la relación matrimonial o análoga, presente o pasada, entre los sujetos activo y pasivo ya ha sido tenida en cuenta por el legislador penal en la tipificación del delito del 173.2 CP, por lo que, de constituir tal relación condición necesaria para apreciar la concurrencia de la agravante de discriminación por género, dicha agravante no podría aplicarse al delito de maltrato habitual, so pena de valorar doblemente esta circunstancia para agravar la responsabilidad penal.

\section{Epílogo}

La LO 1/2015, de 30 de marzo, incorporó "las razones de género" al elenco de causas que podrán dar lugar a la aplicación de la agravante de discriminación del art. 22. $4^{\mathrm{a}} \mathrm{CP}$, generando serias dudas, tanto en la jurisprudencia como en la doctrina científica, acerca de su fundamento y de los requisitos necesarios para su aplicación. A la vista de la jurisprudencia de las Audiencias Provinciales y Tribunales Superiores de Justicia, se constata que, de forma unánime, dicha agravante se ha considerado una circunstancia de carácter subjetivo, supeditando su apreciación, por un lado, a que el sujeto activo del delito fuera un varón y el sujeto pasivo del mismo fuera su esposa, exesposa, pareja o expareja, aun cuando entre ellos no hubiera mediado convivencia, $\mathrm{y}$, por otro, a que el delito se hubiera ejecutado con el propósito de ejercer dominio sobre la mujer, es decir, de situarla en una posición de inferioridad en el seno de la relación. Ello no ha evitado, sin embargo, que se hayan alcanzado soluciones contrapuestas ante supuestos de hecho muy semejantes, lo que pone de manifiesto la incapacidad de esta tesis para resolver los problemas aplicativos que plantea la agravante de discriminación por razones de género, con la consiguiente lesión de la seguridad jurídica. 
Por su parte, la doctrina jurisprudencial del TS ha sufrido una importante evolución, pues, habiendo partido de idéntica posición a la sostenida por la "jurisprudencia menor" -STS 420/2018, de 25 de septiembre-, ha pasado, antes de cumplirse dos meses desde que dictara su primera sentencia sobre el particular, a declarar aplicable la agravante de discriminación por género, fuera del ámbito de las relaciones de pareja, siempre que el sujeto activo cometa el delito con el propósito de discriminar a una mujer por el hecho de serlo. Con esta nueva interpretación, que excluye el requisito de la relación, presente o pasada, matrimonial o análoga entre los sujetos del delito, será posible, a nuestro juicio, aplicar dicha circunstancia junto con la de parentesco, sin incurrir -como venía haciendo la práctica totalidad de la "jurisprudencia menor" y como hiciera el TS en su STS 429/2018, de 25 de septiembre-, en un bis in ídem prohibido, por valorar doblemente la relación de pareja con efectos agravantes, lo que implicará una agravación de la responsabilidad penal en los supuestos de delitos cometidos en el ámbito de la pareja cuando, además, tales delitos tengan una significación discriminatoria por razones de género. Lo anterior permitirá, asimismo, aplicar la agravante objeto de estudio a cualquier delito que se cometa por un varón contra una mujer como manifestación de discriminación en los términos anteriormente indicados, con independencia de la vinculación que exista entre ambos sujetos, supuestos que, de forma inexplicable, no habían sido tenidos en cuenta por la LO 1/ 2004, de 28 de diciembre, de Medidas de Protección Integral contra la Violencia de Género.

Finalmente, en su última sentencia sobre el particular - la STS 99/2019, de 16 de febrero-el TS, corrigiendo cuanto había declarado en sus anteriores resoluciones, abandona su concepción subjetiva de la agravante para conferirle un fundamento puramente objetivo -ajeno al propósito del sujeto activo-, basado en la mayor gravedad del hecho cuando el mismo constituya una manifestación de la arraigada desigualdad existente entre hombres y mujeres, y declara que, para la apreciación de la circunstancia de discriminación por razones de género, es preciso 
probar la existencia de una relación asimétrica entre el sujeto activo -varón- y el sujeto pasivo -mujer-, excluyendo la necesidad de constatar un específico propósito discriminador por parte del autor.

Esta última resolución acierta al establecer, por fin, la ratio de la circunstancia agravante de discriminación por motivos de género en criterios estrictamente objetivos, pues el fundamento de la agravación de la responsabilidad penal que la misma comporta se halla, en nuestra opinión, en el plus de desvalor que supone el atentado a la "igualdad" -como valor merecedor de tutela penal- que deriva de la comisión de un delito como expresión de la posición de superioridad que al hombre -sujeto activo- le otorga la situación de victimización social que la mujer -sujeto pasivo- padece, situación de la que su conducta se aprovecha y en la que repercute. En este sentido, y en contra de la opinión de la doctrina mayoritaria, que la sitúa entre las "causas de naturaleza personal", consideramos que la agravante objeto de estudio es una circunstancia que afecta a la "ejecución material del hecho" y, por lo tanto, es comunicable a los partícipes, esto es, agravará la responsabilidad de quienes hayan tenido conocimiento de ella en el momento de la acción o de su cooperación al delito (art. 65.2 CP).

\section{Bibliografía}

ACALE SÁNCHEZ, M.: La discriminación hacia la mujer por razón de género en el Código penal, Madrid, 2006.

— “Análisis del Código penal en materia de violencia de género contra las mujeres desde una perspectiva transversal", en VILLACAMPA ESTIARTE, C., Violencia de género $y$ sistema penal, Valencia, 2008, pp. 87 a 155.

— “Análisis del Código penal en materia de violencia de género contra las mujeres desde una perspectiva transversal", en REDUR, $\mathrm{n}^{\circ}$ 7, 2009, pp. 37 a 73.

AGUILAR CÁRCELES, M. M.: "Proposición para delinquir. Agravante de discriminación en razón del género y agra- 
vante de reincidencia. El concepto de discapacidad y discapacidad necesitada de especial protección", en MORILLAS CUEVA, L., (dir.): Estudios sobre el Código penal reformado (Leyes Orgánicas 1/2015 y 2/2015), Madrid, 2015, pp. 53 a 71.

ALONSO ÁLAMO, M.: El sistema de circunstancias del delito, Valladolid, 1981.

- "Circunstancias del delito e inseguridad jurídica", en Circunstancias modificativas de la responsabilidad criminal. Cuadernos de Derecho Judicial, Madrid, 1995, pp. 41 a 67.

- "La circunstancia agravante de discriminación", en La ciencia del Derecho penal ante el nuevo siglo. L-H al Prof. Dr. D. José Cerezo Mir, Madrid, 2002, pp. 533 a 542.

BOLDOVA PASAMAR, M. A.: La comunicabilidad de las circunstancias y la participación delictiva, Madrid, 1995.

BORJA JIMÉNEZ, E.: "La circunstancia agravante de discriminación del art. 22. 4", en GONZÁLEZ CUSSAC, J. L. (dir.), Comentarios a la Reforma del Código Penal de 2015, Valencia, 2015, pp. 119 a 123.

CEREZO MIR, J.: Curso de Derecho Penal español. Parte General, Madrid, 2004.

COBO DEL ROSAL, M. y VIVES ANTÓN, T. S.: Derecho penal. Parte General, Valencia, 1999.

COMAS D' ARGEMIR I CENDRA, M. D.: "La ley integral contra la violencia de género: nuevas vías de solución", en BOLDOVA PASAMAR, M. A. y RUEDA MARTÍN, M. A. (coords.), La reforma penal en torno a la violencia doméstica y de género, Barcelona, 2006, pp. 35 a 56.

CÓRDOBA RODA, J.: “Art. 22. 4", en CÓRDOBA RODA, J. y GARCÍA ARÁN, M., Comentarios al Código penal. Parte general, Barcelona, 2011, pp. 290 a 292.

DE LA CUESTA AGUADO, P. M.: "Machismo y violencia. El concepto de «violencia de género penal»", en CASTILLEJO MANZANARES, R (dir.), Violencia de género y Justicia, Santiago de Compostela, 2013, pp. 57 a 66. 
— "Violencia de género: heteroprotección y autoprotección" (pendiente de publicación).

DÍEZ RIPOLLÉS, J. L.: "Naturaleza de las circunstancias modificativas, su referencia a los elementos del delito, y el artículo 60 del Código penal español", en Anuario de Derecho penal y Ciencias Penales, t. XXX, 1977, pp. 597 a 650 .

DOPICO GÓMEZ-ALLER, J.: "Delitos cometidos por motivos discriminatorios: una aproximación desde los criterios de legitimación de la pena", en Revista General de Derecho penal, $\mathrm{n}^{\circ} 4,2005$, pp. 143 a 176.

FARALDO CABANA, P.: "Razones para la introducción de la perspectiva de género en Derecho penal a través de la Ley Orgánica 1/2004, de 28 de diciembre, sobre medidas de protección integral contra la violencia de género", en Revista Penal, $\mathrm{n}^{\circ}$ 17, 2006, pp. 72 a 94.

GARCÍA ÁLVAREZ, P.: El Derecho penal y la discriminación, Valencia, 2003.

GONZÁLEZ CUSSAC, J. M.: Teoría general de las circunstancias modificativas de la responsabilidad criminal, Valencia, 1988.

"Presente y futuro de las circunstancias modificativas", en Circunstancias modificativas de la responsabilidad criminal. Cuadernos de Derecho judicial, Madrid, 1995, pp. 11 a 36.

HORTAL IBARRA, J. C.: "La circunstancia agravante por motivos racistas o discriminatorios (art. 22. $4^{\mathrm{a}} \mathrm{CP}$ ): una propuesta restrictiva de interpretación", en Cuadernos de Política Criminal, $\mathrm{n}^{\mathrm{o}}$ 108, 2012, pp. 31 a 66.

LANDA GOROSTIZA, J. M.: La intervención penal frente a la xenofobia: problemática general con especial referencia al "delito de provocación" del artículo 510 del Código Penal, Bilbao, 1999.

LAURENZO COPELLO, P.: "La discriminación en el Código penal de 1995", en Estudios penales y Criminológicos, $\mathrm{n}^{\circ}$ 19, 1996, pp. 219 a 288. 
MANJÓN-CABEZA OLMEDA, A.: "Violencia de género y doméstica”, en ÁlVAREZ GARCÍA, F. J. (Dir.), Derecho Penal español. Parte Especial, t. I, Valencia, 2011, pp. 489 a 459.

MAQUEDA ABREU, M. L.: “¿Necesitan un móvil discriminatorio las agravantes de sexo/género del art. 22.4 CP?", en SILVA SÁNCHEZ, J. M., QUERALT JIMÉNEZ, J. J., CORCOY BIDASOLO, M. y CASTIÑEIRA PALOU, M. T., Estudios de Derecho penal. Homenaje al profesor Santiago Mir Puig, Montevideo, 2017, p. 703 a 714.

MARÍN DE ESPINOSA CEBALLOS, E.: "El marco normativo de la violencia de género: un estudio de derecho comparado acerca de las leyes de segunda generación y de la ley integral española", en Revista de Derecho Penal y Criminología, n ${ }^{0}$ 17, p. 93 a 126.

- "La agravante de discriminación por razones de género (art. 22. 4 CP)", en Revista electrónica de Ciencia penal y Criminología, $\mathrm{n}^{\circ}$ 20, 2018, pp. 1 a 20.

MIR PUIG, S.: Derecho Penal. Parte General, Barcelona, 2015. MUÑOZ CONDE, F. y GARCÍA ARÁN, M.: Derecho Penal. Parte General, Valencia, 2015.

QUINTERO OLIVARES, G.: Parte General del derecho penal, Navarra, 2010.

PUENTE SEGURA, L.: Circunstancias eximentes, atenuantes $y$ agravantes de la responsabilidad criminal, Madrid, 1997.

REBOLLO VARGAS, R.: "La agravante de discriminación por razón de sexo y su fundamento (art. 22.4 del Código penal)", en Revista General de Derecho penal, n 23, 2015, pp. 1 a 28.

ROIG TORRES, M.: "La delimitación de la «violencia de género»: : un concepto espinoso", en Estudios Penales y Criminológicos, vol. 32, 2012, pp. 247 a 312.

SALINERO ALONSO, C.: Teoría general de las circunstancias modificativas de la responsabilidad criminal y artículo 66 del Código penal, Granada, 2000. 
SAN MILLÁN FERNÁNDEZ, B.: "Reflexiones críticas en torno al delito de coacciones a la huelga", en Revista de Derecho y Proceso penal, $\mathrm{n}^{\circ}$ 52, 2018, pp. 19 a 49.

OREJÓN SÁNCHEZ DE LAS HEREAS, N.: "La agravante genérica de discriminación por razones de género", Tesis Doctoral dirigida por Paz Lloria García, Valencia, 2018, p. 149. Disponible en http://roderic.uv.es/bitstream/handle $/ 10550 / 66676 /$ tesis.pdf? sequence $=1 \&$ isAllowed $=y$ [fecha de última consulta: 13 de febrero de 2019].

RAMON RIBAS, E.: Violencia de género y violencia doméstica, Valencia, 2008.

VILLACAMPA ESTIARTE C.: "Pacto de estado en materia de violencia de género: ¿más de lo mismo?", en Revista electrónica de Ciencia Penal y Criminología, $\mathrm{n}^{\circ} 20$, 2018 , pp. 1 a 38. 